Louisiana State University

LSU Digital Commons

1979

\title{
Motility and Fertility of Stallion Spermatozoa Isolated in Bovine Serum Albumin.
}

Stephen Dale Goodeaux

Louisiana State University and Agricultural \& Mechanical College

Follow this and additional works at: https://digitalcommons.Isu.edu/gradschool_disstheses

\section{Recommended Citation}

Goodeaux, Stephen Dale, "Motility and Fertility of Stallion Spermatozoa Isolated in Bovine Serum Albumin." (1979). LSU Historical Dissertations and Theses. 3435.

https://digitalcommons.Isu.edu/gradschool_disstheses/3435

This Dissertation is brought to you for free and open access by the Graduate School at LSU Digital Commons. It has been accepted for inclusion in LSU Historical Dissertations and Theses by an authorized administrator of LSU Digital Commons. For more information, please contact gradetd@lsu.edu. 


\section{INFORMATION TO USERS}

This was produced from a copy of a document sent to us for microfilming. While the most advanced technological means to photograph and reproduce this document have been used, the quality is heavily dependent upon the quality of the material submitted.

The following explanation of techniques is provided to help you understand markings or notations which may appear on this reproduction.

1. The sign or "target" for pages apparently lacking from the document photographed is "Missing Page(s)". If it was possible to obtain the missing page( $s$ ) or section, they are spliced into the film along with adjacent pages. This may have necessitated cutting through an image and duplicating adjacent pages to assure you of complete continuity.

2. When an image on the film is obliterated with a round black mark it is an indication that the film inspector noticed either blurred copy because of movement during exposure, or duplicate copy. Unless we meant to delete copyrighted materials that should not have been filmed, you will find a good image of the page in the adjacent frame.

3. When a map, drawing or chart. etc., is part of the material being photographed the photographer has followed a definite method in "sectioning" the material. It is customary to begin filming at the upper left hand corner of a large sheet and to continue from left to right in equal sections with small overlaps. If necessary. sectioning is continued again-beginning below the first row and continuing on until complete.

4. For any illustrations that cannot be reproduced satisfactorily by xerography, photographic prints can be purchased at additional cost and tipped into your xerographic copy. Requests can be made to our Dissertations Customer Services Department.

5. Some pages in any document may have indistinct print. In all cases we have filmed the best available copy.

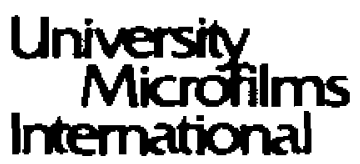

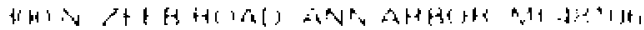

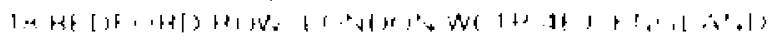


GOODEAUX, STEPHEN DALE

MOTILITY AND FERTILITY OF STALLION SPERMATOZOA ISOLATED IN BOVINE SERUM ALBUMIN

The Louisiana State University and Agricultural and Mechanical Col.
University
PH.D.
1979 Microfilms

International $300 \mathrm{~N}$. Zeeb Road, Ann Arbor. Ml 48106 


\title{
MOTILITY AND FERTILITY OF STALLION \\ SPERMATOZOA ISOLATED IN BOVINE SERUM ALBUMIN
}

A Dissertation

Submitted to the Graduate Faculty of the Louisiana State University and Agricultural and Mechanical College in partial fulfillment of the requirements for the degree of Doctor of Philosophy

in

The Department of Animal Science

\author{
by \\ Stephen Dale Goodeaux \\ B.S., McNeege State University, 1971 \\ M.S., Louisiana State University, 1973 \\ December, 1979
}




\section{ACKNOWLEDGEMENTS}

The author wishes to express his appreciation to his major professor, Dr. J. L. Kreider, for his guidance and assistance throughout the period of graduate study and in preparation of this dissertation. He extends appreciation to members of his advisory committee; Drs. P. E. Humes, D. M. Thrasher, R. A. Godke and E. W. Byrd. Also, the author acknowledges the Department of Animal Science for the financial support during the course of this study.

A special debt of gratitude is due my parents, Mr. and Mrs. E. J. Goodeaux, for their unceasing encouragement during the period of study.

Finally, the author would like to express a very special thanks to his wife, Lora Lana, and daughter, Errin, for their devotion and unending patience during completion of the graduate program. 
TABLE OF CONTENTS

Page

ACKNOWLEDGEMENTS ..........................

LIST OF TABLES .......................... v

LIST OF FIGURES ......................... vi

ABSTRACT..................................... vi

CHAPTER

I . INTRODUCTION ........................ 1

II . REVIEW OF LITERATURE................ 3

sperm cell Parameters............... 3

Acquisition of Motility......... 3

Relationship Between Sperm ceil .................. 5

Percentaqe of Abnormal Spermatozoa... 7

Methods of Enhancing Semen quality...... 13

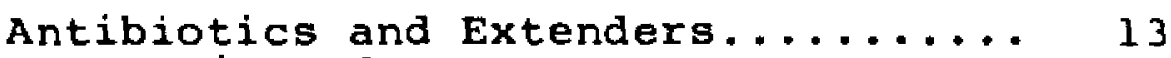

Separation of Spermatozoa.......... 14

Alteration of the Sex Ratio.......... 15

Hormones....................... 16

Immunological Methods............. 18

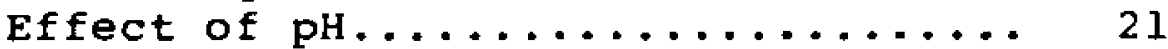

Electrophoresis................. 22

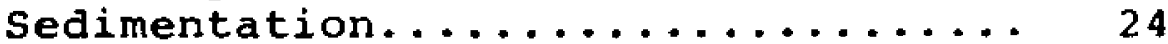

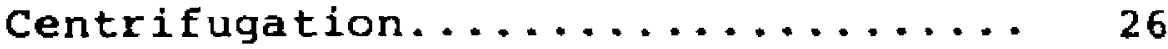

III. MATERIAL AND METHODS................. 29

Experiment 1. Isolation of a Population of Highly Motile Stallion

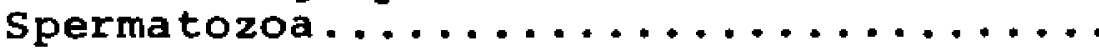

Experiment 2. Effects of the BSA

Isolation, BSA and TYrode's Solu-

tion on Acrosomal Integrity and

Removal of a Fluorescent Label from

Spermatozoa....................

Experiment 3. Fertility of stallion

spermatozoa Isolated in BSA.......... 
TABLE OF CONTENTS (cont'd)

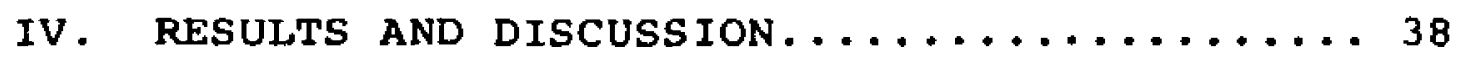

Experiment 1. Isolation of Popula-

tion of Highly Motile Stallion

spermatozoa.................. 38

Experiment 2. Effects of BSA Isolation, BSA and Tyrode's Solution on Acrosomal Integrity and Removal of a Fluorescent

Label from spermatozoa............ 43

Experiment 3. Fertility of stallion

Spermatozoa Isolated in BSA......... 51

General Discussion............... 53

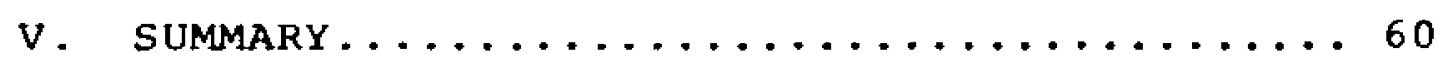

VI. CONCLUSIONS .................... 64

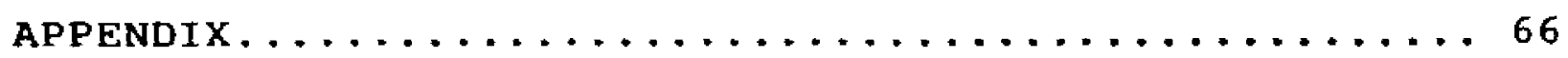

LITERATURE CITED................... 71

vita. .......................... 84 


\section{LIST OF TABLES}

Table

Page

1 Effect of BSA Isolation Procedure on

Percent Motile spermatozoa...............

2 Effect of BSA Isolation Procedure on

Progressive Motility Rate of Spermatozoa.....

3 Effects of BSA Isolation, BSA and

Tyrode's Solution on Percent Motile

spermatozoa .........................

4 Effects of BSA Isolation, BSA and Tyrode's

Solution on Progressive Motility Rate of

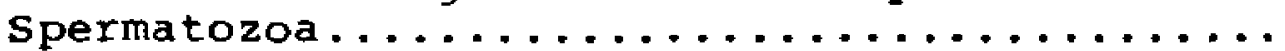

5 Effects of BSA Isolation, BSA and Tyrode's

Solution on Fluorescence of

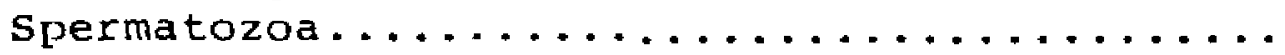

6 Effects of BSA Isolation, BSA and Tyrode's

Solution on Percentage of Spermatozoa with

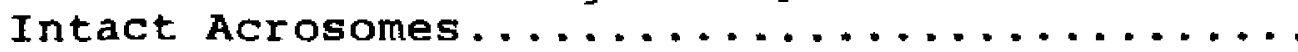

7 Pregnancy and Foaling Rate of Mares

Inseminated with Isolated and Control

Spermatozoa......................... 


\section{LIST OF FIGURES}

Figure

Page

1 Experimental Design for Experiment 1....... 30

2 Experimental Design for Experiment $2 \ldots \ldots . \ldots 34$

3 Isolated and Control Treatments used for

Fertility Test in Experiment $3 \ldots \ldots \ldots 36$ 


\section{ABSTRACT}

Semen from three mature stallions was used in an initial experiment in an attempt to isolate a population of highly motile spermatozoa. An ejaculate of semen was collected with an artificial vagina from each stallion at 7-day intervals for 35 days. Immediately following collection, semen samples were evaluated for percentage of motile spermatozoa and rate of progressive motility (scale 1 to 4). Two $\mathrm{ml}$ of semen were layered over $6 \mathrm{ml}$ of 38 bovine serum albumin (BSA) in $13 \times 125 \mathrm{~mm}$ columns at room temperature (RMT) or in a warm water bath (WB). After $30 \mathrm{~min}$, the top semen layer and upper and lower halves of the BSA fraction were separately withdrawn from all columns and reevaluated. In both the RMT and WB isolation columns, percent motile spermatozoa and rate of progressive motility decreased ( $\mathrm{P}<.01$ ) in the top semen layer as compared to initial values for these parameters. Percentage of motile spermatozoa in the lower BSA fractions increased $(P<.01)$ from 41.78 at collection to 58.7 and 65.7 for the RMT and WB treatments, respectively. Also, the progressive motility rate of spermatozoa in lower BSA fraction of the RMT and WB treatments increased $(P<.05)$ from 2.9 to 3.3 and 3.7 , respectively.

In a second experiment, a total of 40 ejaculates from four mature stallions was utilized to determine the effects of BSA isolation on the removal of tetracycline 
hydrochloride ( $\mathrm{T}-\mathrm{HCl})$ and on the acrosomal integrity of spermatozoa. Based on a scale 0 to 4 , the initial fluorescent score of spermatozoa labeled with T-HCl was 3.9. Following BSA isolation, the fluorescent scores of spermatozoa in the top semen layer and upper and lower halves of the BSA fraction decreased $(P<.05)$ to $3.0,0.9$ and 0.7 , respectively. Also, there was a significant decrease in fluorescence of spermatozoa suspended in 38 BSA. Acrosomal integrity of spermatozoa was similar for all treatments. However, spermatozoa in lower fractions of BSA isolation columns had fewer ( $P<.05)$ intact acrosomes than spermatozoa $\left(50\right.$ and $\left.200 \times 10^{6}\right)$ suspended in $B S A$ and all concentrations of spermatozoa suspended in Tyrode's solution.

In a third experiment, 30 Quarter Horse mares were artificially inseminated to compare fertility of spermatozoa isolated in BSA with raw semen diluted with either BSA or Tyrode's solution. Pregnancy rate for 10 mares inseminated with $100 \times 10^{6}$ live isolated spermatozoa was not different from that of mares inseminated with the same number of control spermatozoa. Foaling rates were 70,60 and 408 for the isolated, BSA and Tyrode treatment groups, respectively. Also, more male foals were produced by mares inseminated with isolated spermatozoa than mares inseminated with control spermatozoa. 


\section{CHAPTER I}

\section{INTRODUCT ION}

Interest in horses and horse related industries has been increasing rapidly during the past few years. In spite of this growth of the industry, reproductive efficiency in the horse is lowest of any species of farm animals. Factors which influence the reproductive efficiency of the horse include: lack of selection for fertility, greater variation in female reproductive patterns, imposition of an artificial breeding season, failure to recognize that the stallion is a major factor affecting infertility and current attitudes of some breed organizations with respect to artificial insemination.

Recognition of the problems which cause decreased fertility in the horse is critical to solving the problem. One of the major areas of concern in equine reproduction, as well as in other species is the failure to develop semen evaluation criteria which are highly correlated to actual fertility. However, researchers have attempted to correlate several semen characteristics to fertility in the stallion. These characteristics include: sperm cell concentration, percentage of active spermatozoa and the percentage of primary and secondary abnormalities of spermatozoa in an ejaculate. The conventional approach to the problem of semen fertility has been to use extenders and antibiotics which provide a more favorable environment for 
sperm cell survival and control bacterial growth in semen.

A recent technique for the isolation of semen fractions rich in human $\mathrm{Y}-\mathbf{s}$ permatozoa may provide an alternative approach to improving semen quality (Ericsson et al., 1973). This technique is based on the principle that highly motile and morphologically normal cells will penetrate a viscous medium which provides a barrier to non-motile and morphologically abnormal spermatozoa. Adaption of this technique for use with stallion spermatozoa could result in higher conception rates using artificial insemination. Since studies with human semen have shown that this procedure alters the ratio of $X$ - and $Y$-bearing spermatozoa, sex preselection is a possible added incentive for adapting this technique for use on stallion spermatozoa. The study reported herein was conducted to determine if a population of highly motile spermatozoa could be isolated from stallion semen and, if so, to evaluate the fertility of these spermatozoa when used for artificial insemination. Also, the sex of foals produced by insemination of mares was recorded to determine if sex preselection was accomplished. 


\section{CHAPTER II}

\section{REVIEW OF IITERATURE}

During the past decade, there has been a considerable increase in research directed toward improving low reproductive efficiency of horses. The bulk of this work has emphasized study concerning reproductive problems associated with the mare. Greater variation in reproductive patterns, extended periods of sexual receptivity and difficulty of synchronizing breeding with ovulation are some of the major problem areas in equine reproduction. However, it is important to realize that a significant amount of the cause of low reproductive rates reported for horses is undoubtedly the fault of the stallion. Although studies in the literature on male fertility and particularly on semen of farm animals are numerous, comparable information on the horse is not available.

\section{Sperm Cell Parameters.}

Acquisition of Motility. Spermatozoa which are produced in the germinal epithelium of the seminiferous tubules of the testes do not acquire the ability to move until they reach the epididymis. The region within the epididymis where spontaneous sperm cell motility first occurs varies with species. Very little motility of spermatozoa is present in the epididymis of the rat (Turner et al. , (1978) and hamster (Morton et al., 1978). In other species 
however, spontaneously motile spermatozoa were obtained from the caput (rabbit) and corpus (bull and man) regions of the epididymis. Samples from the cauda epididymis of the rabbit and bull contained numerous motile spermatozoa, where as in man, most of the spermatozoa from this area were intensely motile (Morton et al., 1978).

Although the potential for motility is acquired in the epididymis, epididymal spermatozoa remain immotile in situ. Gray (1928) reported that absence of sperm cell motility within the genital tract was due to such factors as high $\mathrm{CO}_{2}$ concentrations, reduced $\mathrm{pH}$ and crowding of spermatozoa. However, more recent evidence has demonstrated that the lack of $\mathrm{O}_{2}$ and hexose substrate are the principle factors which contribute to immotility of spermatozoa in vivo (Bishop and Mathews, 1952; Mann, 1954). Furthermore, Morton et al. (1974) reported that quiescent hamster spermatozoa removed from the cauda epididymis became motile following the addition of calcium ions and cyclic nucleotides. Shifts in nucleotide levels were also reported by Cascieri et al. (1976) prior to the acquisition of motility of cauda epididymal bovine spermatozoa. The addition of calcium ions or cyclic nucleotides had little or no effect on inducing motility since sperm were already partially motile. These regearchers suggest that increases in bull sperm cell motility at ejaculation result from reduction of mechanical restraint through dilution. 
Likewise, Storey (1975) suggested that motility of rabbit sperm cells is initiated at ejaculation by release from physical restraint and access to oxygen. More recent studies by Turner et al. (1978) indicated that dilution of epididymal plasma is as important as addition of ions to initiate motility of quiescent spermatozoa from the cauda epididymis of rats. Also, glycerylphosphorylcholine and carnitine in epididymal plasma inhibited sperm cell motility. Turner et al. (1978) further suggested that high sperm cell concentration and low ion availability cause immotility of epididymal spermatozoa. However, at ejaculation, the accessory secretions add diluent and electrolytes to the epididymal fluid allowing stimulation or activation of sperm cell motility.

Relationship Between Sperm Cell Motility and Fertility. Although spermatozoa acquire the potential to move within the duct of the epididymis, the acquisition of motility does not insure that spermatozoa have the ability to fertilize ova. Nevertheless, sperm cell motility is considered to be the best single criterion for evaluation of sperm cell viability and is the characteristic of semen used most extensively for evaluating potential fertility. However, attempts to relate the initial motility of spermatozoa to fertilizing capacity have been less than successful. Williams and Savage (1927) considered motility of spermatozoa a poor indication of fertility because many factors 
may impede the movement of spermatozoa from highly fertile bul1s, while diseased or deformed spermatozoa from subfertile bulls are often highly motile. Numerous other studies have shown no significant relationship between initial motility and fertility (Swanson and Herman, 1941; Swanson and Herman, 1944; Cheng et al., 1949; Cupps et al., 1953; Bishop et al., 1954).

Although the literature contains several studies which state that the relationship between motility and fertility is minor, Lasley (1951) observed a significant positive correlation $(r=.31)$ between the percentage of motile spermatozoa and fertility. More recently, chandler et al. (1978) found that the percentage of progressively motile spermatozoa was positively correlated to 60 to 90 day nonreturn rate.

The property of motility most nearly correlated with fertility of bull semen is apparently survival of vigorous motility over time, and this characteristic is termed longevity (Swanson and Herman, 1941; Swanson and Herman, 1944; Bishop et al., 1954). Using the split ejaculate technique, Margolin et al. (1943) related longevity to fertility by inseminating cows with fresh semen or semen that had been stored at $5 \mathrm{C}$ for 24 hours. Analysis of breeding records on 10 sires and 306 cows showed a highly significant positive correlation $(r=.69)$ between longevity of spermatozoa and conception rate. Analysis of data from over 12,000 cows inseminated with semen from 27 
bulls ( 305 ejaculates) resulted in a positive correlation coefficient ( $r=.84$ ) between the time required for spermatozoa to lose all activity at $37 \mathrm{C}$ and percent conception based on 60 to 90 day non-return rate (Ludwick et al.. 1948). In later studies, similar findings were reported by Buckner et al. (1954).

Although longevity of sperm cell survival is positively correlated to fertility of bovine spermatozoa, attempts to correlate this semen trait with fertility in species other than the bull have not been reported in the literature.

Percentage of Abnormal Spermatozoa. Another characteristic of semen which has been given considerable attention in the evaluation of potential fertility of the male is the percentage of abnormal spermatozoa in the ejaculate. Many different types of spermatozoal abnormalities have been described and classified. According to Dott (1975), the form of the spermatozoon can be affected at a number of different stages in its development which ascribe a particular deformity. Primary abnormalities occur as a failure of spermatogenesis and involves the head of the spermatozoon. Secondary abnormalities result during spermiogenesis, while tertiary deformities are produced prior to or after ejaculation. Both secondary and tertiary abnormalities involve the midpiece and/or tail of the spermatozoon.

Although several abnormalities have been described, the relationship between variations in morphology and 
fertility is not clear. Bielanski (1951) found an inverse correlation ( $r=-.5$ ) between the percentage of primary abnormalities and fertility of stallion semen. Haag (1959) also reported a negative correlation between the percentage of abnormal spermatozoa and pregnancy rate in mares. In a more recent study, Bielanski (1975) suggested that $30 \%$ of the total spermatozoa in the stallion ejaculate may have secondary abnormalities without necessarily lowering fertility. However, primary abnormalities in greater than 10 of the spermatozoa always result in a reduction in fertility.

Numerous studies have attempted to correlate the percentages of abnormal spermatozoa and fertility of bulls. Early observation of Williams and Savage (1927) suggested that greater than $15 \%$ abnormal spermatozoa in an ejaculate caused a reduction in fertility. In contrast, Anderson (1941) stated that 108 of the sperm cells in an ejaculate from fertile animals are abnormal. Subsequently, Trimberger and Davis (1942) reported that 27 dairy bulls with greater than 900 normal spermatozoa per thousand had significantly better breeding records than bulls with fewer normal spermatozoa. Uzu et al. (1976) found an inverse relationship between numbers of morphological abnormalities and fertility of 10 bulls, while Rob and Rozinek (1976) reported that bulls with disturbed spermiogenesis had lowered fertility. Recently Chandler et al. (1978) concluded that 648 of the total variation in fertility attributed to bulls 
was accounted for by the percentage of primary abnormalities in an ejaculate.

McKenzie and Phillips (1954) attempted to correlate morphologically abnormal spermatozoa and fertility in the ram. Results indicated that rams with greater than 158 abnormal sperm cells had reduced fertility.

Specific primary abnormalities which have been studied quite extensively are those which involve the acrosome. This structure which arises from a secretion product of the Golgi apparatus (Austin and Bishop, 1958) is of particular interest because of its critical role in fertilization. Hancock (1949) observed that ejaculates of seven Freisian bulls with known fertility problems were dominated by spermatozoa with a peculiar deformity located on the lateral aspect of the anterior pole of the sperm head. Other semen characteristics of these bulls were within normal ranges and gave no indication of seminal inadequacy. However, matings to 108 females resulted in no pregnancies. This condition had been previously reported by Tieunissen (1946) who observed that the abnormality was present on 82 to 908 of the spermatozoa from 60 bulls which were sterile or had low fertility. These findings were later confirmed by Rollinson and Makinson (1949).

Defects of the sperm acrosomal cap termed the "knobbed acrosome", which are characterized by an excessively stained region at or near the apex of the head of the spermatozoon, have also been shown to cause sterility in bulls (Donald 
and Hancock, 1953; Hancock, 1953; Blom and Birch-Anderson, 1962).

Saacke et al. (1968) have described a number of acrosomal cap abnormalities of bovine spermatozoa related to subfertility. Defects may reflect subtle as well as major deviations in nuclear morphology. The most prevalent acrosomal abnormality had lateral and anterior protruding vesicles. These lateral vesicles may account for the ruffled and incomplete acrosomes on ejaculated sperm. Another defect was characterized by an evagination into the sperm nucleus near the apex of the sperm head. Both defects were present on the spermatozoa of subfertile bulls with 40 to 60 non-returns to first services.

Roussel et al. (1972) reported that the percentage of absent or missing acrosomes was negatively correlated $(P<.01)$ with motility and number of live spermatozoa. Also, the percentage of abnormal acrosomes was negatively correlated with concentration and motility of spermatozoa. These data suggest that acrosamal morphology should be included as part of a semen quality test for bulls.

Acrosomal cap abnormalities have also been reported on boar spermatozoa (Wohlforth, 1961). Unsatisfactory breeding performance of two boars was traced to a acrosomal defect present on 80 to 1008 of ejaculated spermatozoa. Following genealogical investigations, a simple recessive inheritance appeared to be the cause of this defect. 
Buttle and Hancock (1965) found no difference in sperm concentration between normal boars and boars possessing the knobbed acrosomal defect; however, semen from affected boars showed lower motility than semen from normal boars. None of 11 sows conceived when mated to affected boars. Also, intravaginal insemination of 12 sows and intraoviductal insemination of nine sows with affected semen failed to result in pregnancy. It was suggested that sterility associated with the knobbed acrosomes was due to failure of spermatozoa to attach to ova.

According to Hancock (1952), acrosomal abnormalities of spermatozoa are a product of faulty spermatogenesis, but the aging phenomenon and post-mortern changes are associated with morphological changes in the acrosome of mature spermatozoa. Post-mortem changes of bull spermatozoa began with a progressive lifting or swelling of the acrosome on the sperm head, followed by shrivelling and ruffling of the edges of the acrosome which lead to a complete detachment of the acrosomal cap. Other spermatozoa were characterized by a complete disintegration of the acrosome at the equatorial plate. In later studies, Austin and Bishop (1958) observed similar changes in the acrosome of bull, hamster, guinea pig and mouse spermatozoa following cessation of motility.

The sequence of events associated with sperm cell death and aging reported in the previous studies coincide with morphological changes induced by different methods 
of handling semen. Iype et al. (1963) noted that the acrosome of bovine and buffalo spermatozoa was completely removed when spermatozoa were suspended in water and subjected to cold treatment (OC). Also, the acrosome of bovine spermatozoa showed varying degrees of disintegration following fixation with methanol. Saacke and Marshall (1968) compared the types of acrosomal morphology found in raw and diluted semen. Deterioration of acrosomal morphology started as a loss of the apical ridge, followed by breakdown of the cell membrane and slight to severe swelling of the anterior acrosomal cap. Next, there was a distinct ruffling of the acrosome and breakdown of the outer acrosomal membranes. Late stages of deterioration were characterized by loss of electron dense ground substance in the anterior acrosomal cap. Similar changes in acrosomal morphology have been reported by Wells and Awa (1970) following incubation of ejaculates at $37 \mathrm{C}$. The percentage of abnormal acrosomes increased from an initial value of 16.28 to 67.18 after $12 \mathrm{hr}$ incubation, and progressed to 88.78 after 24 hours. The percentage of capless spermatozoa did not change during the first 12 hr incubation, but the percentage of spermatozoa with ruffled and elevated acrosomes increased rapidly. In a subsequent study, Chandler et al. (1978) found that the percentage of intact acrosomes after $3 \mathrm{hr}$ incubation at $37 \mathrm{C}$ was positively correlated $(r=.87)$ to fertility. Results strongly indicated that percentage of intact acrosomes after $3 \mathrm{hr}$ incubation 
was as accurate an indicator of semen quality as was a battery of seminal quality parameters.

Although most observations have suggested that the correlation between the percentage of abnormal spermatozoa and fertility is unclear, Van Demark et al. (1945) suggested that the number of abnormal spermatozoa in an ejaculate is extremely critical. Based on results of methylene-blue reduction tests, as well as glucose loss and lactic acid gain during incubation, these researchers concluded that structurally abnormal spermatozoa apparently utilize nutrients similar to normal spermatozoa.

Methods of Enhancing Semen Quality

Antibiotics and Extenders. Almquist (1943) introduced the use of antibiotics in semen dilutes as a means of reduciny bacteria contamination and for controlling the incidence of veneral diseases. In a later study, Knodt and Salisbury (1946) used sulfa drugs to reduce bacterial growth in diluted semen. Numerous other studies have utilized antibiotics to control bacteria and enhance livability of bovine spermatozoa (Knodt and Salisbury, 1946; Foote and Bratton, 1950; Almquist, 1951; willett and Ohms, 1955; zaugg and Almquist, 1973).

The use of antibiotics and extenders have also been reported to improve the longevity of stallion semen used for artificial insemination (Bowen, 1969; Pickett and Voss, 
1972; Back et al., 1975; Nishikawa, 1975; Pickett et al.. 1975, Pickett and Voss, 1975). For optimal use of AI, an extender is required to use antibiotics for control of disease, to control losses of spermatozoa during insemination of small volumes and to enhance and prolong longevity of spermatozoa.

Separation of Spermatozoa. Other methods of enhancing semen quality have included: addition of various diluents to obtain the optimum number of spermatozoa for maximal fertility, deep freezing of semen in various sizes of ampules and plastic straws, and addition of sugars and glycerol to prevent damage to sperm cells during the freezing process. These methods are protective in nature or provide a more favorable environment for sperm cell survival. However, the technique of Ericsson et al. (1973) may provide an alternative approach to improving semen quality. The technique involved layering a quantity of human semen over a bovine serum albumin (BSA) solution in glass columns and allowing spermatozoa a predetermined time interval to penetrate the medium. Ericsson suggests that the process creates an interface between the semen and isolation medium such that it separates motile from nonmotile and morphologically normal from abnormal spermatozoa. Ross et al. (1975) concluded that BSA gradients provided a method for selecting morphologically normal sperm of high motility. Soupart (1975) and Glaub et al. (1976) 
observed that seminal debris declined dramatically in successive BSA fractions and that lower fractions were virtually devoid of extraneous material. Also, BSA fractions contained a select population of the fastest swimming spermatozoa; and only very few dead spermatozoa were present in the lower BSA fractions.

\section{Alteration of the Sex Ratio}

The previous studies have demonstrated that mammalian semen is somewhat less than homogeneous and further suggest the possibility of obtaining a select population of spermatozoa with greater fertility. Since a part of the heterogenity of semen is associated with differences in sex chromatin of $\mathrm{X}$ - and $\mathrm{Y}$-chromosome bearing spermatozoa, it is logical to suppose that sex preselection and thus alteration of the sex ratio is within the realm of possibility.

Man's control of the sex ratio is one of the most interesting, unsolved problems in biology. From a practical standpoint, the control of the ratio would permit the production of an optimum proportion of males and females and thus take advantage of phenotypic differences in sex linked and sex influenced traits. The use of sex preselection would also result in increased selection pressure and optimize genetic progress by insuring that male progeny as potential sires and female progeny as potential replace- 
ments would come from the best sire $x$ dam crosses (Foote and Miller, 1971).

Hohmones. Several different hormone treatments have been utilized in attempting to alter the primary sex ratio, i.e.. the ratio of males:females at conception. White and DeCosta (1960) administered injections of .625 to $6.25 \mathrm{mg}$ cortisone twice weekly to rats for 6 to 25 weeks and found that sex ratios for 1 itters were not significantly different from control values. The sex ratio for litters receiving $5 \mathrm{mg}$ cortisone was 31 males: 15 females; however, the relatively small numbers limited meaningful conclusions.

Efficacy of altering the sex ratio with injections of estrogen and progesterone was tested by Hahn and Hays (1963). Injections of estrogen and progesterone administered to pregnant rats, ovariectomized at day 8 of pregnancy, in dosages near physinlogical levels decreased the secondary sex ratio to 80.4 males per 100 females and increased the ratio to 122.2 males in intact females. A decrease in litter size of treatment groups suggested that exogenous hormones brought about preferential mortality or survival of one sex.

vladimirsjka (1964) observed that the addition of androgens to semen for insemination of sows, cows, and rabbit does increase the percentage of males almost twofold. In a separate study, vladimirskaja (1966) reported increases in the frequency of males by factors of 1.3 to 
$2.0,1.9$ and 2.3 to 3.0 by adding methyl testosterone to boar, bull and rabbit semen, respectively. Harcenko (1967) noted that low doses (.025 or $.125 \mathrm{gr})$ of methyl testosterone added to the semen diluent caused predominance of male pigs, while larger doses resulted in more female pigs. More recently, Petrenko and Tkachuk (1970) inseminated ewes and rabbit does with semen treated with methyl testosterone and reported sex ratios of progeny were 62.8 and 64.48 males, respectively.

Another approach to the use of hormones to alter the sex ratio was reported by Volosevic (1967), who inseminated cattle, sheep and sows with semen diluted with extracts of the testis, placenta and spleen. A predominance of female offspring were produced by addition of extracts of the testis and placenta, but not spleen, to the semen of bulls, rams, boars and rabbits.

since previous studies utilizing hormones to alter sex ratios suggested that hormones exerted a differential effect on the $x$ - and $x$-bearing spermatozoa, Beck et al. (1976) investigated this possibility by determining the effects of steroid hormones on motility and selective migration of $\mathrm{X}$ - and $\mathrm{Y}$-bearing human spermatozoa. Sperm cell migration after $15 \mathrm{~min}$ was not significantly different among the different hormones (testosterone, estrogens and gestagens in $20 \mathrm{HSA}$ ) however; after $30 \mathrm{~min}$, a significant difference was observed between hormones stimulating sperm cell motility (estrogen and testosterone) and those 
suppressing motility (gestagens). Also, the percentage of $Y$-bearing spermatozoa increased from 46.28 at $10 \mathrm{~mm}$ migration distance to 638 at $90 \mathrm{~mm}$ distance.

Immunological Methods. Identification of a specific antigen, located on either the X- or Y-bearing spermatozoa, capable of inducing the formation of antibodies and of reacting in some detectable manner with the induced antibody offers an alternative approach to the separation of $\mathrm{X}$ - and $\mathrm{Y}-$ bearing spermatozoa. Stambaugh and Buckley (1971) discovered a new isozyme $\left(\mathrm{x}_{4}\right)$ of lactic dehydrogenase (LDH), the enzyme which catalyzes the final step in anaerobic glycolysis, that may be characteristic of male producing spermatozoa. Intrauterine insemination of rabbit does with spermatozoa carrying the $x_{4}$ isozyme produced 68 males and 32 females (a male: female ratio of 2.12 ), thus suggesting that the $\mathrm{x}_{4}$ isozyme may be used as an assay for distinguishing between $X-$ and $Y$-bearing spermatozoa.

Another immunological method of separating $x$ - and Y-bearing spermatozoa was reported by Bennett and Boyse (1973), who prepared an antiserum to the $H-Y$ antigen of rat spermatozoa. Insemination with spermatozoa treated with antiserum resulted in 45.48 males compared with 538 from naturally mated control rats. Results suggest that sperm cells containing the $\mathrm{Y}$-chromosome have the $\mathrm{H}-\mathrm{Y}$ antigen or have more $H-Y$ antigen on their surface than $X$-bearing sperm cells. 
Since the avian male has hormologous sex chromosomes and the female has heterologous sex chromosomes, it is logical to believe that antigens on bird spermatozoa may be similar to antigens on one genotype of mammalian spermatozoa. Burkov (1971) suggested that it might be possible to use bird sperm cells as an immunizing antigen. Sex ratio of offspring produced by rabbits, intravaginally immunized with bird spermatozoa, differed ( $P<.05$ ) from control offspring, 41.8 and 52.18 males, respectively. Alteration of the sex ratio was interpreted as a result of immune attack against $Y$-bearing mammalian sperm, or a preferential protection of X-bearing spermatozoa. Assumptions of Burkov were further investigated by Hancock (1978) who reported that antisera which showed anti-bird spermatozoa activity did not show comparable activity against rabbit spermatozoa, and thus concluded that rabbit and bird spermatozoa were antigenetically dissimilar. The sex ratio of offspring produced by rabbit does inseminated with sperm plus anti-bird spermatozoa sera (79 males and 107 females) differed significantly from inseminations with sperm plus normal sera (50 males and 28 females), thus suggesting a preferential reaction of anti-bird spermatozoa antibodies with either $x$ - or $Y$-bearing rabbit spermatozoa.

Timing of Insemination. Clinical observations suggest that the sex of the fetus may be influenced by the time relationship between insemination and ovulation. In the 
middle of the fertility period, the sex ratio is presumed to be approximately equal, and as the time interval between insemination and ovulation increases or decreases, there is a predominance of one sex. Hammond (1934) reported a marked increase in the sex ratio of rabbits as the time of insemination approached ovulation. Further studies by Blandau and Jordan (1941) produced a higher percentage of male rats from insemination at various times (6 to $12 \mathrm{hr}$ ) after ovulation. Hart and Moody (1949) concluded that the time factor between insemination and ovulation directly influences the sex ratio in rats. In contrast, vickers (1969) found no significant difference between sex ratios of mice produced from control matings and the sex ratio of offspring produced from matings with delayed fertilization times.

Several of the previous studies have suggested that insemination of females relative to the time of ovulation may cause a predominance of one offspring. Therefore, it would seem logical that artificial insemination of cattle $12 \mathrm{hr}$ after the onset of standing heat might result in a higher percentage of male offspring. Data from 1,783 single born Holstein calves from 26 herds did not show any alteration of the natural sex ratio (Gardner, 1950). Ballinger (1970) found no deviation of normal sex ratios for calves conceived from inseminations early or late in estrus. Furthermore, Foote (1977) observed that the sex ratio for over 35,000 single births in 2,254 dairy herds 
was not different among the five dairy breeds. However, there was a slight preponderance of male calves, 50.88 , compared with female calves, 49.28 , in all breeds.

Effect of pH. A German physician, Felix Unterberger, noted that many of his patients with fertility problems had a high acid content in the vagina. Since it was known that vaginal lavage with bicarbonate solution helped to overcome sterility or failure to conceive in dogs, cows and horses, and since bicarbonate washings are completely harmless, Unterberger used a bicarbonate douche to combat vaginal acidity. Following treatment, the child conceived was more frequently a boy (Warren, 1940). Since these observations suggested that alkaline conditions at conception favored the birth of boys, it was logical to suppose that acid conditions would favor the birth of girls. Roberts (1940) tested the effects of acid or alkali douches on the sex ratio of rats. Douching females with lactic acid ( 2 and $3 \%$ ) before mating was effective in increasing the proportion of females, while sodium bicarbonate ( 3 and 58 ) increased the proportion of males. Cole et al. (1940) and Quisenberry and Chandiramani (1940) were unsuccessful in altering the sex ratios of rabbits or rats using an acid or alkali douche prior to mating. Negative results were also reported by McPhee and Eaton (1942). 
Casida and Murphree (1942) tested the effect of direct contact of spermatozoa with lactic acid or sodium bicarbonate on the $\mathrm{zex}$ ratio of rabbits. No modification of the expected sex ratio was observed by treatment of spermatozoa with acid or alkali solutions.

Weir (1953) suggested that the $\mathrm{pH}$ of the dam's reproductive tract may cause preferential selection of $\mathrm{x}$ - or Y-bearing mouse spermatozoa. According to his hypothesis, cervical mucous with a relatively high $\mathrm{pH}$ tends to favor $\mathrm{Y}$-bearing spermatozoa and low $\mathrm{pH}$ favors $\mathrm{X}$-bearing spermatozoa. Further testing of this hypothesis by kleegman (1954) showed that human cervical mucous is acidic around midcycle and at ovulation the $\mathrm{pH}$ is highest. Inseminations at the time of ovulation produced a preponderance of males, and inseminations 2 days prior to ovulation resulted in predominantly female offspring. Later, Cohen (1967) was unable to confirm these results. Furthermore, Diasio and Glass (1971) concluded that small changes in $\mathrm{pH}$ did not influence the migration of human Y-bearing spermatozoa.

Electrophoresis. Electrophoresis is based on the principle that charged particles migrate through a solution under the influence of an electric field. Mudd et al. (1929) were the first to study spermatozoa in a electrophoretic apparatus and to note that migration was determined by a net negative surface charge on the sperm cell tail. 
If $X$ - and $Y$-bearing spermatozoa have opposite surface charges, electrophoresis would facilitate their separation. Koltzoff and Schroder (1933) reported that electrophoresis of horse or rabbit spermatozoa caused some spermatozoa to move toward the anode, while others moved toward the cathode and some showed no movement. Insemination of rabbit does with anode migrating spermatozoa produced 6 females, cathode migrating spermatozoa produced 4 males and one female. Insemination with spermatozoa showing no movement during electrophoresis produced two male and two female offspring. Lewin (1956) and Gordon (1957) reported that insemination of anode migrating rabbit sperm produced a high proportion of male offspring, and insemination with cathode migrating spermatozoa produced a high proportion of female offspring. However, Vesselinovitch (1960) and Sevine (1968) were unable to confirm that electrophoresis would separate $X$ - and $Y$-bearing spermatozoa.

Additional information on electrophoresis of spermatozoa was presented by Bangham (1961) who described several types of spermatozoa based on movement during electrophoresis. Spermatozoa with a more negative charge on their tail than on their head moved toward the anode with the tail projected foremost; these spermatozoa were referred to as "tail anode" spermatozoa. A second type of spermatozoa swam toward the anode because of a more negative charge on the head than on the tail, and were designated as "head anode" spermatozoa. Movement of these spermatozoa 
could be controlled by strength of electric field and $\mathrm{ph}$. Therefore, Bangham suggested that a zone type of electrophoresis would result in a more homogeneous separation.

In further studies of electrophoresis, Hafs and Boyd (1971) utilized different types of electrophoretic cells to separate rabbit and bull spermatozoa. Their data showed that sex ratios in rabbits were altered when anode or cathode migrating spermatozoa were used for insemination. Later studies in which cows were inseminated with spermatozoa that had migrated to the anode or cathode did not influence the percentage of male calves (Hafs and Boyd, $1974)$.

Studies thus far suggest that electrophoretic separation of $X$ - and $Y$-bearing spermatozoa is not feasible. However, Douglas et al. (1976) utilized a similar principle in an attempt to separate human or rabbit spermatozoa with cation and anion exchange chromatography. Sex ratios of rabbits produced from cation exchange treated and controlled spermatozoa were $48.7,51.3$ and $48.3 \%$, respectively. The authors concluded that exchange chromatography did not effectively separate $X$ - and $Y$-bearing spermatozoa.

Sedimentation. Since $x$-chromosome bearing spermatozoa of several species have a greater mean dry mass than $\mathrm{Y}$ chromosome bearing spermatozoa (Harvey, 1946; Oresnik, 1970; Sumner and Robinson, 1976), theoretically the heavier $x$-spermatozoa should sediment more rapidly than the lighter 
Y-spermatozoa. Following sedimentation of rabbit spermatozoa, Bhattacharya (1962) reported that spermatozoa in lower fractions had significantly larger heads than spermatozoa in the upper fractions. Insemination with spermatozoa from the upper, middle and lower fractions produced 77.4, 54.7 and 28.28 males, respectively. Bedford and Bibeau (1967) were unable to confirm changes in sex ratio after sedimentation of rabbit spermatozoa.

Separations of spermatozoa by sedimentation has also been reported for farm animals. Schilling (1966) and Krazanowski (1970) fractioned bovine spermatozoa in a medium that preserved motility and sperm cell survival. Cows inseminated with lower Eractions of spermatozoa produced significantly more females than control cows. However, Bhattacharya et al. (1966) and Knaack (1970) were unable to alter the sex ratio of calves by insemination of sedimented bovine spermatozoa. Petrenko (1968) sedimented ram spermatozoa in egg yolk-glucose-citrate medium and observed that spermatozoa in the upper portion had significantly smaller heads than spermatozoa in the lower portion. Ewes inseminated with upper and lower portions produced 65.5 and 31.18 males, respectively. These values were significantly different from control ratios.

In a somewhat different approach to sedimentation, Kiddy and Bailey (1973) adjusted atmospheric pressure to sediment rabbit spermatozoa. However, sex ratios of offspring produced by treated spermatozoa were 
not significantly different from normal values.

Another means of separating $X$ - and $Y$-spermatozoa by sedimentation is froth flotation (More o'Farrall et al., 1968). As with other sedimentation procedures, froth flotation attempts to separate "heavy" and "light" spermatozoa. A standardized air flow is bubbled through semen, the fraction of spermatozoa separated with air bubbles is termed the froth fraction and the remaining portion is designated the sink fraction. Sex ratios of litters produced by control, froth and sink rabbit spermatozoa were not significantly different.

Centrifugation. Since $x$-chromosome bearing spermatozoa have a larger volume and/or a higher density than $\mathrm{Y}-$ bearing spermatozoa, centrifugation has been utilized in an attempt to enhance sedimentation of $\mathrm{X}$ - and $\mathrm{Y}$-bearing spermatozoa. Lindahl (1956) produced more male calves by insemination of light spermatozoa after counter-streaming centrifugation of bovine spermatozoa. However, in a second study, Lindahl (1958) was unable to confirm that counter-streaming centrifugation effectively separated $x-$ and $\mathrm{Y}$-bearing spermatozoa.

After centrifugation of human spermatozoa in discontinuous sucrose gradients, Rhode et al. (1975) observed four bands of differing densities. A higher percentage of Y-bearing spermatozoa were present in the first two fractions of lower densities. 
Density gradient centrifugation of rabbit spermatozoa has been reported by Schilling and Thormahlen (1976). Insemination with light spermatozoa produced more male progeny and insemination with heavy spermatozoa produced more females. Furthermore, if less than 58 of the total spermatozoa in the top or botton portion was inseminated, the percentage of males and females, respectively, was increased.

A major problem with centrifugation is that it is detrimental to motility and viability of spermatozoa. Consequently, Shastry et al. (1977) attempted to develop a method to protect spermatozoa during separation by centrifuging human spermatozoa layered on Ficoll-sodium metrizoate density gradients. Based on the fluorescence of the $Y$-body, the sediment was rich in $Y$-bearing spermatozoa and the interface between solutions consisted predominately of $\mathrm{X}$-bearing spermatozoa. Also, the motility and viability of these spermatozoa was only slightly reduced.

During the past 50 years, attempts to separate $x$ - and $Y$-chromosome bearing spermatozoa have failed or have resulted in only limited success. However, the recent technique of Ericsson et al. (1973) for the isolation of fractions rich in human Y-spermatozoa has been quite successful. These researchers have isolated fractions of human spermatozoa that are predominately (858) Y-chromosome bearing spermatozoa. Their results have been confirmed by 
numerous studies (Soupart, 1975; Brever et al.. 1977; David et al.. 1977; Dmowski et al.. 1979b). Therefore, the possibility of sex control on a clinical basis might be practical in the near future.

Studies in the literature on male fertility are numerous, while attempts to enhance semen quality and/or to separate a more homogeneous population of spermatozoa have been somewhat limited, especially in the stallion. One of the primary weaknesses of stallion semen is its high percentage of non-motile and abnormal spermatozoa. Since these abnormal spermatozoa metabolize energy at a similar rate as normal cells and may, therefore, produce a detrimental effect on the survival of normal spermatozoa, the most logical approach to improving stallion semen quality would be to isolate a fraction of highly motile spermatozoa that is free of abnormal spermatozoa and extraneous materials. The experiment reported herein was conducted to determine if a population of highly motile spermatozoa could be isolated from stallion semen and, if so, to evaluate the fertility of these spermatozoa when used for artificial insemination. Also, the sex and vigor of foals at birth will be recorded to evaluate the effects of insemination with BSA isolated spermatozoa on these parameters. 
CHAPTER III

MATERIALS AND METHODS

Experiment 1. Isolation of a Population of Highly Motile Stalion Spermatozoa.

Three mature stallions (two Quarter Horses and one Thoroughbred) ranging in age from 6 to 12 :ears were used as experimental animals in the initial expiriment. An ejaculate of semen was collected from each of the stallions by the artificial vagina method at 7-day irtervals for 5 weeks. Immediately following collection, semen samples were examined microscopically in the laboratory. Each ejaculate was evaluated for percent motile spermatozoa and rate of progressive motility (scale 1 to 4 by light microscopy at 200 magnification. Subsequently, ejaculates were split with half of the semen being uled in the isolation procedure while the remaining half served as a control (figure 1). A final concentration of 150 to $200 \times 10^{6}$ spermatozoa/ml was obtained by diluting senen samples having relatively high concentrations $1>200 \times 10^{6}$ spermatozoa/ml) with Tyrode's solution. The pH of the Tyrode's solution was adjusted to 7.4 with 18 Tris buffer. ${ }^{2}$ Modification of the bilayer separation procedure of Ericsson et al. (1973) was required in the present experiment.

$1_{\text {TC }}$ Tyrode Solution $(10 X)$, No. 5555-72, DIFCO Laboratories, Detroit, MI.

Tham, T-395, Fisher Scientific Co., Fair Lawn, NJ. 


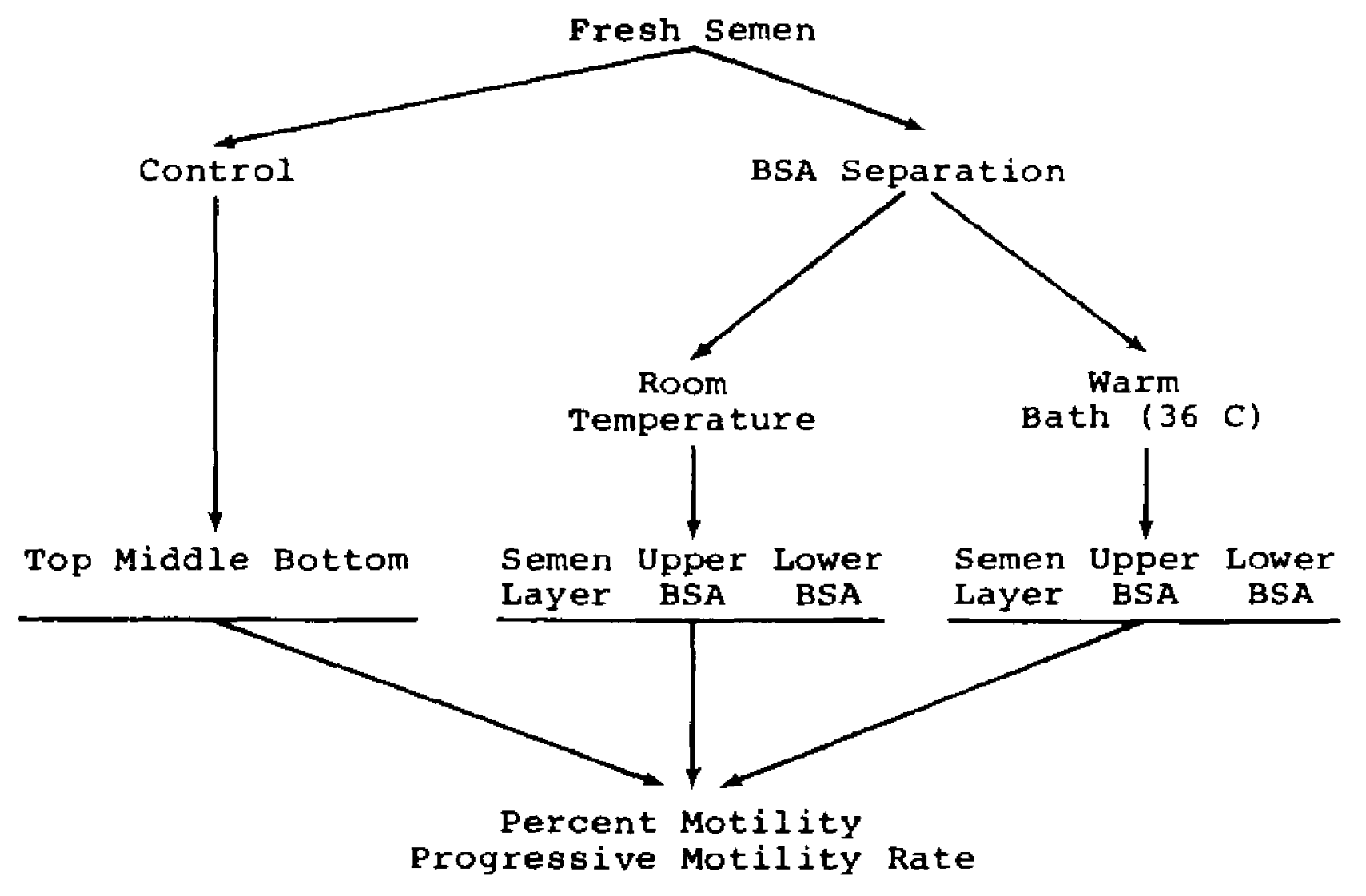

Figure 1. Experimental design for Experiment 1. 
Modifications consisted of layering $2 \mathrm{ml}$ of $\mathrm{raw}$ semen or $2 \mathrm{ml}$ of raw semen diluted with Tyrode's solution over $6 \mathrm{ml}$ of $38 \mathrm{BSA}^{3}$ in $13 \times 125 \mathrm{~mm}$ columns. The 32 BSA solution was prepared by diluting commercially prepared BSA with Tyrode's solution. For the purpose of determining the effects of temperature on the isolation procedure, isolation columns were run at room temperature (RMT) and additional columns were placed in a warm water bath (WB) at $36 \mathrm{c}$. After $30 \mathrm{~min}$, the top semen layer and the upper and lower halves of the BSA fraction were withdrawn from each column and pooled in respective tubes. Each of the different fractions was evaluated for percent motile spermatozoa and rate of progressive motility.

Sperm cell parameters were examined statistically using analysis of variance. The statistical model included the following sources of variation: horse, week, treatment, position, as well as horse $x$ week and treatment $x$ position interaction effects. Means for sperm cell parameters were compared with the initial estimates according to Dunnett's procedure (Steel and Torrie, 1960).

Experiment 2. Effects of the BSA Isolation, BSA and Tyrode's Solution on Acrosomal Integrity and Removal of a Fluorescent Label from Spermatozoa.

${ }^{3}$ Albumin, Bovine, No. A-4878, Sigma Chemical Co.. st. Louis, Mo. 
A second experiment was designed to examine the effects of the isolation procedure on the acrosomal integrity of spermatozoa and on the removal of a fluorescent label from spermatozoa.

A total of 40 ejaculates were obtained from four mature stallions (two Quarter Horses, one Thoroughbred and one Shetland pony) ranging in age from 5 to 12 years. Immediately following collection, semen samples were evaluated for percent motile spermatozoa and rate of progressive motility as described in Experiment 1. Percentage of spermatozoa with intact acrosomes was determined after the method of Saacke and Marshall (1968). Semen samples were examined by Nomarski differential interference contrast microscopy $(1000 x)$. Spermatozoa with intact acrosomes were characterized by the presence of a distinct apical ridge at the anterior acrosomal cap.

The antibiotic tetracycline hydrochloride (T-HCl) ${ }^{4}$ is a fluorophor which acts as a supravital stain when added to mammalian spermatozoa (Ericsson and Baker, 1967). Since T-HCl was removed from spermatozoa in the uteri and oviducts of estrous females, but was not removed in the uteri of pseudopregnant females or females with a

${ }^{4}$ Polyotic, American Cyanamide Company, Princeton, NJ. 
functional corpus Iuteum, Ericsson (1967 a, b) suggested that removal of $\mathrm{T}-\mathrm{HCl}$ from spermatozoa could be used as a non-biological test for capacitation. Therefore, adaptation of this technique was utilized to determine if the isolation procedure initiates sperm cell capacitation.

Fresh semen samples were labelled with 6 ug T-HC1/10 spermatozaa. Following $10 \mathrm{~min}$ incubation, $2 \mathrm{ml}$ of semen $\left(100 \times 10^{6}\right.$ spermatozoa/ml) were layered over $6 \mathrm{ml}$ of 38 BSA. In order to test the effects of dilution on removal of $\mathrm{T}-\mathrm{HCl}, 50,100$ and $200 \times 10^{6}$ labelled spermatozoa were suspended in $6 \mathrm{ml}$ BSA and $6 \mathrm{ml}$ Tyrode's solution (figure 2). After $30 \mathrm{~min}$, the top semen layer and upper and lower halves of the BSA fraction from separation columns were withdrawn and pooled in respective tubes. Also, an aliquot from each column in the BSA and Tyrode's treatments was placed in separate tubes. Subsequently, each of the different fractions was evaluated for percent motile spermatozoa, progressive motility rate, percentage of intact acrosomes and a fluorescent score. Presence of T-HCl was asgessed with an Olympus BH microscope equipped with a Fluorescence BH-RFL 100 watt mercury vapor illuminator. Fluorescence was based on a scale 0 to 4 with 0 , indicating no fluorescence, 1 , only the tail of the apermatozoa fluorescencing, and 2,3 and 4 indicating weak, moderate and bright fluorescence of the entire sperm celis, respectively. 


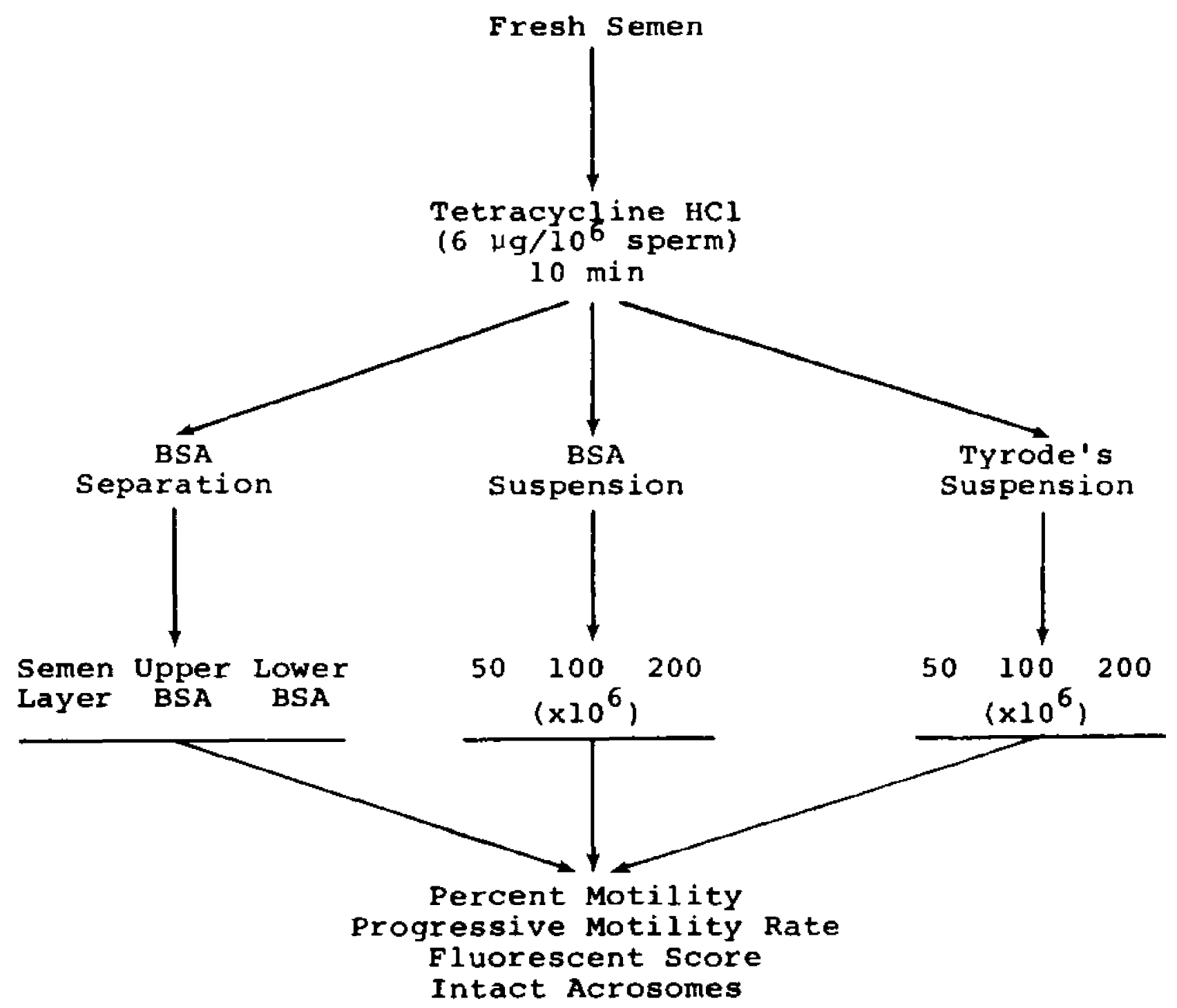

Figure 2. Experimental design for Experiment 2. 
Results were examined statistically using analysis of variance. Statistical model included ejaculate, combination and error sources of variation. The initial estimate, each position in the isolation columns and each concentration of spermatozoa suspended in BSA or Tyrode's solution constituted a treatment combination. Differences between treatment means (combinations) were determined with Duncan's New Multiple Range Test (Steel and Torrie, 1960).

Experiment 3. Fertility of Stallion Spermatozoa Isolated in BSA.

A third experiment was designed to compare the fertility of spermatozoa isolated in BSA with that of raw semen diluted with either Tyrode's solution or BSA. Semen was obtained from three mature stallions according to methods previously described. Based on results from the initial experiment, the isolation procedure was carried out in a warm water bath $(36 \mathrm{C})$. Isolation of spermatozoa was accomplished by layering $2 \mathrm{ml}$ of semen containing $100 \mathrm{x}$ $10^{6}$ live spermatozoa over $6 \mathrm{ml}$ of 38 BSA in $13 \times 125 \mathrm{~mm}$ columns. The correct sperm cell concentration was obtained by dilution of semen with Tyrode's solution. Thirty Quarter Horse mares were randomly assigned to three treatment groups (figure 3) for fertility tests in this experiment. During estrus, mares were palpated per rectum to determine follicular development and ovulation. Based 


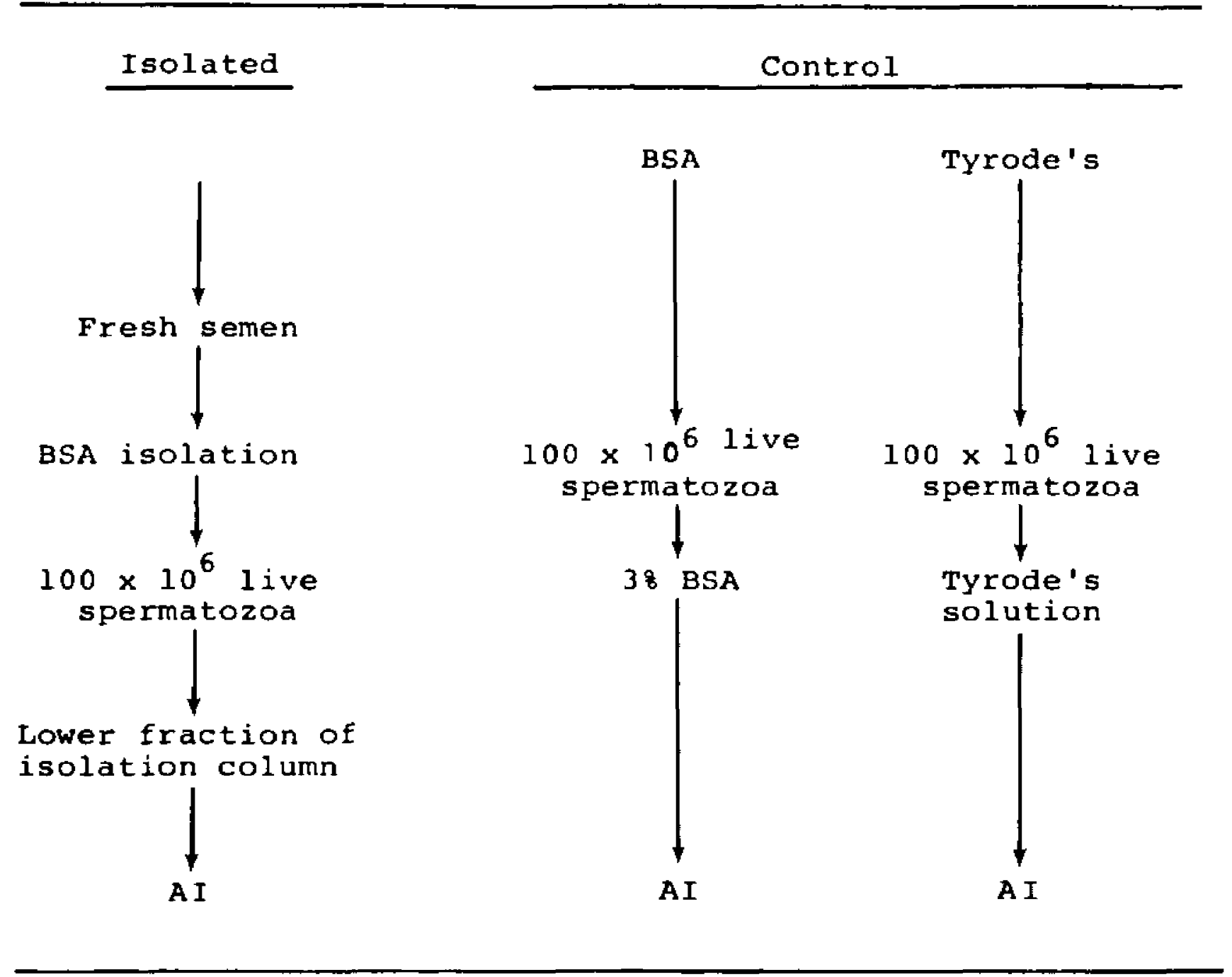

Figure 3. Isolated and control treatments used for fertility test in Experiment 3. 
on palpation data, each mare was inseminated beginning on day 2 or 3 of estrus and every other day thereafter until ovulation was detected. In the first treatment group, 10 mares were inseminated with $100 \times 10^{6}$ live spermatozoa suspended in Tyrode's solution. Group 2 consisted of 10 mares which were inseminated with $100 \times 10^{6}$ live spermatozoa suspended in $3 \%$ BSA. The third group of 10 mares was inseminated with $100 \times 10^{6}$ live spermatozoa isolated in the lower BSA fractions of the separation columns. An equal volume of $15 \mathrm{ml}$ was used for insemination of all mares. After two estrous cycles, mares that had not conceived were removed from their respective treatment groups and bred according to conventional breeding procedures. Pregnancy was confirmed by palpation after 45 days. Also, the sex and vigor of foals at birth were recorded. Pregnancy and foaling rates of mare groups were tested by Chi-square analysis. 


\section{CHAPTER IV}

\section{RESULTS AND DISCUSSION}

Experiment 1. Isolation of a Population of Highly Motile stalíion Spermatozoa

Data for the effects of BSA isolation on percent motile spermatozoa are presented in table 1. Analysis of variance revealed a significant ( $P<.01)$ treatment effect. Also, the effects of position, i.e., top semen layer, and upper and lower halves of the BSA fraction, and treatment $x$ position interaction effects were highly significant. Consequently, the results are discussed by position within treatment, rather than by treatment. Immediately after collection, the mean value for percent motile spermatozoa was 41.7. Following the $30 \mathrm{~min}$ isolation period, there was a marked decrease $(P<.01)$ in motility of the top, middle and bottom fractions of the control semen compared with the initial estimate. This decline in sperm cell motility was expected, since control semen consigted of a column of raw semen, at room temperature, which was subsequently divided into top, middle and bottom fractions. White (1968) reported that sperm cells are deprived of oxygen by letting semen stand in long narrow tubes and that oxidation of the lactic acid cannot take place. Therefore, this decline in percent motility of control spermatozoa was possibly due to a drop in pH caused by an 
TABLE 1. EFFECT OF BSA ISOLATION PROCEDURE ON PERCENT MOTILE SPERMATOZOA ${ }^{a}$

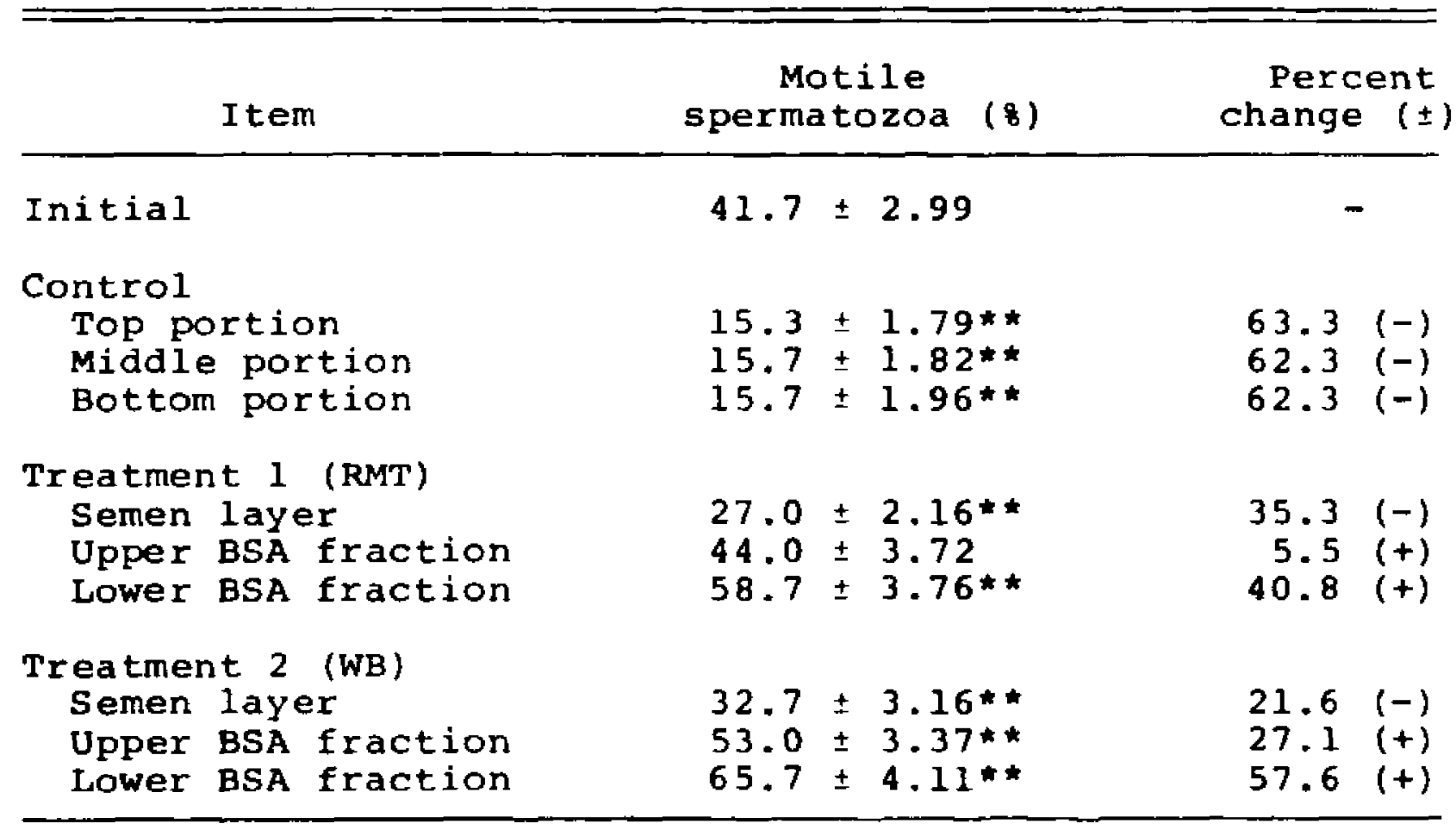

$a_{\text {Mean }} \pm \mathrm{SE}$.

* Difference significant $(P<.01)$ from initial mean. 
accumulation of lactic acid. Faust et al. (1976) reported a decline in motility and a corresponding decline in $\mathrm{pH}$ for bovine spermatozoa layered over BSA. However, less change in $\mathrm{pH}$ would be expected with stallion semen since equine spermatozoa are relatively poor anerobes (Mann et al., 1963). In the present experiment, there was also a decline in spermatozoal activity in the upper semen layer of both RMT and WB treatments. However, the percent motile spermatozoa in the lower BSA fraction increased $(P<.01)$ to 58.7 and 65.7 for the RMT and WB treatments, respectively. Also, there was a 27.18 increase $(P<.01)$ in motile spermatozoa in the upper BSA fraction for the WB treatment. Motility of the upper BSA fraction for the RMT columns was not significantly different from the initial estimate. Increases in sperm cell motility as a result of BSA isolation in the present experiment are similar to increases previously reported for human (Ericsson et al.. 1973; Ross et al., 1975) and bovine spermatozoa (Faust et al... 1976).

There were also significant changes in progressive motility rate of spermatozoa following BSA isolation (table 2). Analysis of the data showed a significant treatment, as well as position and treatment $x$ position interaction effects. Based on a scale 1 to 4 , the average progressive motility rates of control spermatozoa were 1.6, 1.7 and 1.7 for the top, middle and bottom fractions, 
TABLE 2. EFFECT OF BSA ISOLATION PROCEDURE ON PROGRESSIVE MOTILITY RATE OF SPERMATOZOA

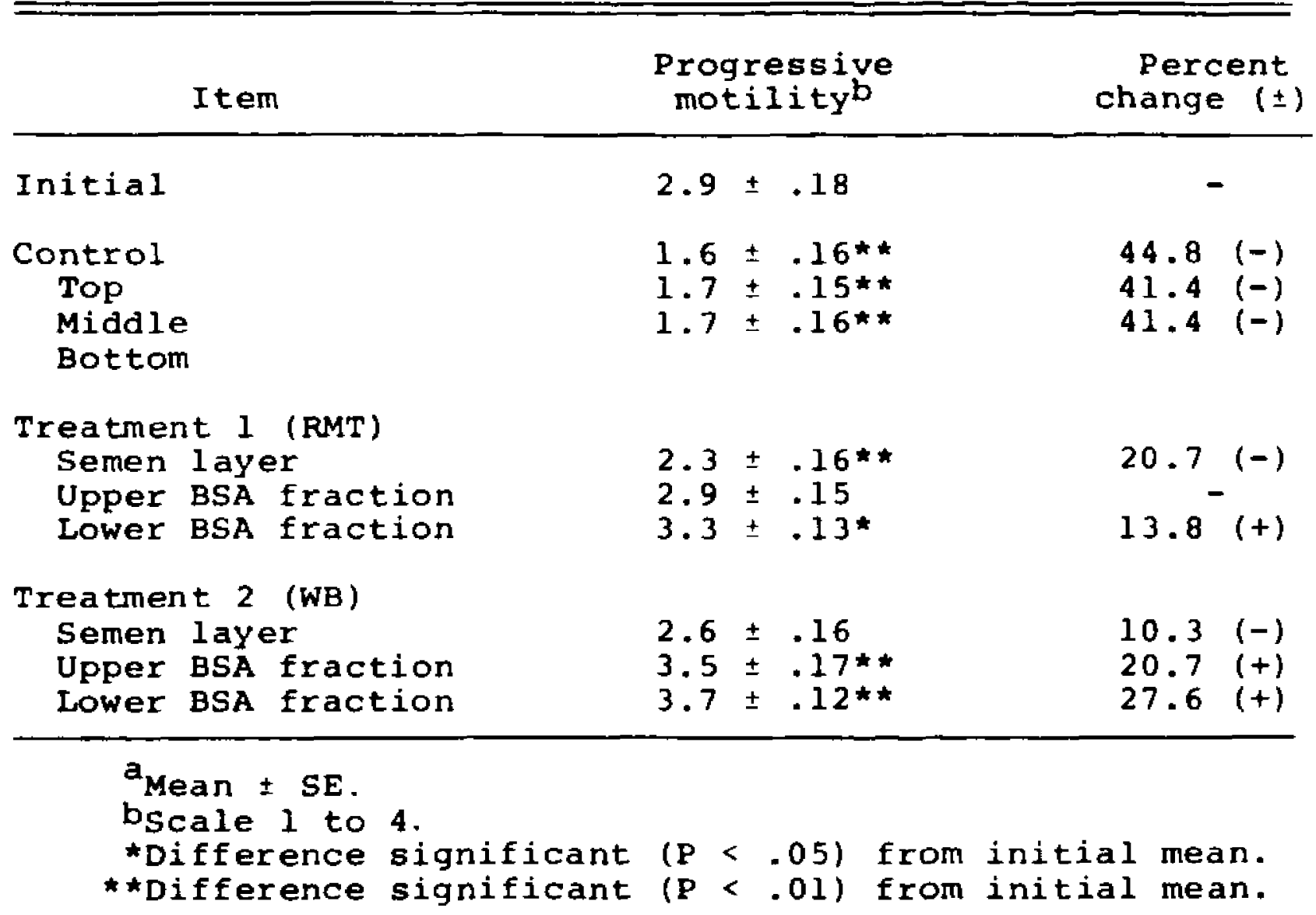


respertively. Although there was no change in progressive rate of spermatozoa from the upper BSA fraction of the RMT columns compared with the initial estimate, progressive rate of spermatozoa from the lower BSA fraction increased $(\mathrm{P}<.05)$ to 3.3. Also, progressive rate of spermatozoa from the upper and lower halves of the BSA fraction of WB columns increased $(P<.01)$ to 3.5 and 3.7 , respectively. Observations in the present experiment are similar to those reported by Glaub et al. (1976) who found that motility score of human spermatozoa in successive BSA fractions were clearly higher than the top semen fraction or parent semen control.

Although not studied systematically in this experiment, routine microscopic examination showed noticeably fewer abnormal spermatozoa and less debris in the lower BSA fractions of both RMT and WB isolation columns. Similar observations were reported by Ericsson et al. (1973), who suggested that the process successfully selects a population of spermatozoa that are almost entirely motile and morphologically normal. These data suggest that stallion spermatozoa respond similar to human and bovine spermatozoa when layered over BSA. 
Experiment 2. Effects of BSA Isolation; BSA and Tyrode's Solution on Acrosomal Integrity and Removal of a Fluorescent Label from Spermatozoa

Since the isolation of equine spermatozoa in BSA resulted in acceleration of motility rate, a characteristic commonly associated with spermatozoa which have undergone the initial stages of capacitation, a second experiment was conducted in an attempt to investigate the possibility that capacitation had been initiated. Removal of the supravital fluorescent stain $\mathrm{T}-\mathrm{HCl}$ from spermatozoa was used as an indicator of possible initiation of capacitation. Also, since it is recognized by some researchers that capacitational changes must occur prior to initiation of an acrosome reaction, the percentage of spermatozoa with intact acrosomes was determined.

Data for percent motile spermatozoa and progressive motility rate of spermatozoa were recorded in the second experiment to confirm that the isolation procedure was functioning as reported in experiment 1 . The mean initial value for percent motile spermatozoa was 50.0 (table 3 ). Following the $30 \mathrm{~min}$ isolation period, there was a significant decrease $(P<.05)$ in motile spermatozoa in the top semen layer of BSA isolation columns compared with the initial estimate. This decrease was similar to the decline in sperm cell motility reported for spermatozoa in the top semen layer of the isolation columns in experiment 1 . Percent motile spermatozoa in the upper and lower halves of 
TABLE 3. EFFECT OF BSA ISOLATION, BSA AND TYRODE'S SOLUTION ON PERCENT MOTILE SPERMATOZOA

\begin{tabular}{|c|c|c|c|}
\hline I tem & sperm & $\begin{array}{l}\text { otile } \\
\text { atozoa (\%) }\end{array}$ & $\begin{array}{l}\text { Percent } \\
\text { change }( \pm)\end{array}$ \\
\hline Initial & 50.0 & $\pm 5.9^{b}$ & \\
\hline $\begin{array}{l}\text { BSA isolation } \\
\text { Semen layer } \\
\text { Upper BSA fraction } \\
\text { Lower BSA fraction }\end{array}$ & $\begin{array}{l}24 \cdot 1 \\
54.5 \\
65.2\end{array}$ & $\begin{array}{r} \pm \quad 6.7^{\mathrm{c}} \\
\pm \quad 11.4^{\mathrm{d}} \\
\pm \quad 9.9^{\mathrm{e}}\end{array}$ & $\begin{aligned} 51.8 & (-) \\
8.8 & (+) \\
30.4 & (+)\end{aligned}$ \\
\hline $\begin{array}{l}\text { BSA suspension } \\
50 \times 10^{6} \text { spermatozoa } \\
100 \times 10^{6} \text { spermatozoa } \\
200 \times 10^{6} \text { spermatozoa }\end{array}$ & $\begin{array}{l}32.8 \\
32.6 \\
32.0\end{array}$ & $\begin{array}{l} \pm 10.4 \mathrm{f} \\
\pm \quad 10.1 \mathrm{f} \\
\pm \quad 9.1^{\mathrm{f} .9}\end{array}$ & $\begin{array}{ll}34.4 & (-) \\
34.8 & (-) \\
36.0 & (-)\end{array}$ \\
\hline $\begin{array}{l}\text { Tyrode's suspension } \\
50 \times 10^{6} \text { spermatozoa } \\
100 \times 10^{6} \text { spermatozoa } \\
200 \times 10^{6} \text { spermatozoa }\end{array}$ & $\begin{array}{l}29.5 \\
27.9 \\
26.1\end{array}$ & $\begin{array}{l}9.19 \\
9.8^{h} \\
9.6^{C, h}\end{array}$ & $\begin{array}{ll}41.0 & (-) \\
44.2 & (-) \\
47.8 & (-)\end{array}$ \\
\hline
\end{tabular}

$\mathrm{a}_{\text {Mean }} \pm \mathrm{SE}$.

$b, c, d, e, f, g, h$ Means with the same letter are not significantly different. 
the BSA fraction of isolation columns increased $(P<.05)$ to 54.4 and 65.2 , respectively. These data, as well as results of the initial experiment, confirm that a population of highly motile spermatozoa can be isolated from stallion semen.

Since the motility of spermatozoa (50, 100 and $200 \times 10^{6}$, suspended in BSA and Tyrode's solution was lower $(P<.05)$ than the initial estimate and upper and lower halves of the BSA fraction from the isolation columns, increases in percent motile spermatozoa following BSA isolation apparently were not due to exposure of spermatozoa to the isolation medium.

Initial value for progressive motility rate (scale 1 to 4) of spermatozoa was 2.9 (table 4). After the 30 min isolation period, the progressive rate of spermatozoa in the upper and lower halves of the BSA fraction from isolation columns increased $(P<.05)$ to 3.4 and 3.7 , respectively. In contrast to the reduction in percent motile spermatozoa, suspension of spermatozoa (50 and $100 \times 10^{6}$, in BSA significantly increased progressive motility rate.

Although values were lower than the progressive rate of spermatozoa isolated in BSA, these results suggest a stimulating effect of BSA on the progressive motility rate of spermatozoa. Harrison et al. (1978) found that sperm cell motility was preserved in the presence of serum 
TABLE 4. EFFECT OF BSA ISOLATION, BSA AND TYRODE'S SOLUTION ON PROGRESSIVE MOTILITY RATE OF SPERMATOZOA

\begin{tabular}{|c|c|c|}
\hline I tem & $\begin{array}{c}\text { Progressive } \\
\text { rate }\end{array}$ & $\begin{array}{c}\text { Percent } \\
\text { change }( \pm)\end{array}$ \\
\hline Initial & $2.9 \pm .4^{\mathrm{c}}$ & - \\
\hline $\begin{array}{l}\text { BSA isolation } \\
\text { Semen layer } \\
\text { Upper BSA fraction } \\
\text { Lower BSA fraction }\end{array}$ & $\begin{array}{l}2.5 \pm .6^{\mathrm{d}, \mathrm{h}} \\
3.4 \pm .4 \mathrm{e}^{\mathrm{e}} \\
3.7 \pm .3^{\mathrm{f}}\end{array}$ & $\begin{array}{ll}13.8 & (-) \\
17.2(+) \\
27.6 & (+)\end{array}$ \\
\hline $\begin{array}{l}\text { BSA suspension } \\
50 \times 10^{6} \text { spermatozoa } \\
100 \times 10^{6} \text { spermatozoa } \\
200 \times 10^{6} \text { spermatozoa }\end{array}$ & $\begin{array}{l}3.1 \pm .69 \\
3.2 \pm .69 \\
3.1 \pm .6 \mathrm{C} .9\end{array}$ & $\begin{aligned} 6.9 & (+) \\
10.3 & (+) \\
6.9 & (+)\end{aligned}$ \\
\hline $\begin{array}{l}\text { Tyrode's suspension } \\
50 \times 10^{6} \text { spermatozoa } \\
100 \times 10^{6} \text { spermatozoa } \\
200 \times 10^{6} \text { spermatozoa }\end{array}$ & $\begin{array}{l}2.6 \pm .7 \mathrm{~h} \\
2.5 \pm .5^{\mathrm{h}} \\
2.4 \pm .6^{\mathrm{d}}\end{array}$ & $\begin{array}{ll}10.3 & (-) \\
10.3 & (-) \\
17.2 & (-)\end{array}$ \\
\hline
\end{tabular}

$a_{\text {Mean }} \pm \mathrm{SE}$.

bscale 1 to 4 .

$c, d, e, f, g, h$ Means with the same letter are not significantly different. 
albumin and that human or bovine serum albumin was consistently the most effective. More recently, suter et al. (1979) reported that 38 human serum albumin enhanced the motility of human spermatozoa.

Isolation of spermatozoa in 38 BSA significantly affected the removal of T-HCl from spermatozoa. Mean fluorescent scores for all treatments were lower $(P<.05)$ than the initial value (table 5). Immediately after incubation of spermatozoa with $\mathrm{T}-\mathrm{HCl}$, the initial fluorescent score was 3.9. Following BSA isolation, there was a significant reduction in fluorescence of spermatozoa in successive fractions. The fluorescent scores for the top semen layer, and upper and lower halves of the BSA fraction decreased $(P<.05)$ to $3.0,0.9$ and 0.7 , respectively. Also, fluorescence of spermatozoa in the upper and lower halves of the BSA fraction was significantly lower than that of spermatozoa in the top semen layer of the isolation columns.

In order to determine if $\mathrm{T}-\mathrm{HCl}$ was physically removed from spermatozoa simply by dilution rather than an effect of the isolation procedure, different sperm cell concentrations $\left(50,100\right.$ and $\left.200 \times 10^{6}\right)$ were suspended in BSA or Tyrode's solution. After $30 \mathrm{~min}$, the mean fluorescent scores for spermatozoa suspended in BSA were $1.7,1.9$ and 2.0. Corresponding scores for spermatozoa suspended in Tyrode's solution were $2.9,2.8$ and 2.8 for 50,100 and 
TABLE 5. EFFECTS OF BSA ISOLATION, BSA AND TYRODE'S SOLUTION ON FLUORESCENCE OF SPERMATOZOA

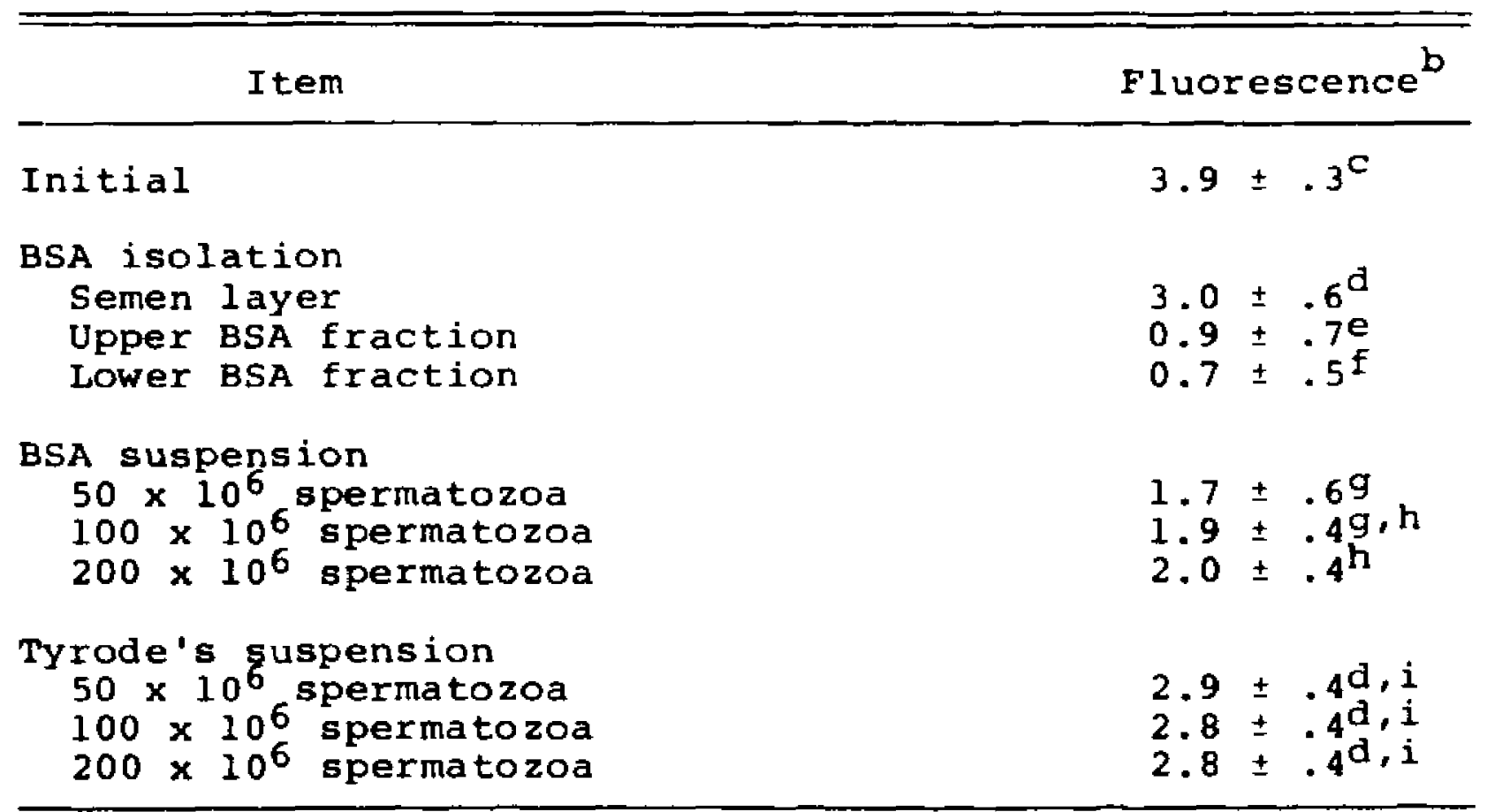

$a_{\text {Mean }} \pm \mathrm{SE}$.

bscale 0 to 4 .

$c, d, e, f, g, h, i_{\text {Means with the same letter are not }}$ significantly different. 
$200 \times 10^{6}$ spermatozoa, respectively. These values were significantly lower than the initial gcore. In addition, scores for spermatozoa suspended in BSA were lower ( $<.05)$ than scores for spermatozoa in Tyrode's solution. Since fluorescence scores of spermatozoa exposed to Tyrode's solution were not significantly lower than those of spermatozoa in the top semen layer of the isolation columns, the decrease in fluorescence was apparently due to a physical removal of excess $\mathrm{T}-\mathrm{HCl}$ rather than any physiological reaction with the surface of spermatozoa. Ericsson and Baker (1967) reported that incubation of $\mathrm{T}-\mathrm{HCl}$ labelled bovine spermatozoa in Tyrode's solution did not remove T-HCl. However, isolation of spermatozoa in BSA or dilution with BSA possibly results in a physiological change or reaction, on the sperm cell surface that effectively removes T-HCl from spermatozoa.

As shown in table 6 , the percentage of spermatozoa with intact acrosomes following BSA isolation and incubation in BSA or Tyrode's solution were similar. However, the percentage of spermatozoa with intact acrosomes in the lower BSA fraction of the isolation columns was lower (P < .05) compared with corresponding values for 50 and $200 \times 10^{6}$ spermatozoa in BSA, but was not different from $100 \times 10^{6}$ spermatozoa in BSA. Also, the percentage of spermatozoa with intact icrosomes in the lower BSA fraction of isolation columns was significantly lower than values 
TABLE 6. EFFECT OF BSA ISOLATION, BSA AND TYRODE'S SOLUTION ON PERCENTAGE OF SPERMATOZOA WITH INTACT ACROSOMES ${ }^{\mathrm{a}}$

\begin{tabular}{|c|c|}
\hline I tem & $\begin{array}{l}\text { Intact } \\
\text { Acrosome }(8)\end{array}$ \\
\hline Initial & $94.5 \pm 2.4^{b, c}$ \\
\hline $\begin{array}{l}\text { BSA isolation } \\
\text { Semen layer } \\
\text { Upper BSA fraction } \\
\text { Lower BSA fraction }\end{array}$ & $\begin{array}{l}94.5 \pm 1.7^{b}, c \\
94.3 \pm 2.1^{b}, c \\
93.8 \pm 2.1^{c}\end{array}$ \\
\hline $\begin{array}{l}\text { BSA suspension } \\
50 \times 10^{6} \text { spermatozoa } \\
100 \times 10^{6} \text { spermatozoa } \\
200 \times 10^{6} \text { spermatozoa }\end{array}$ & $\begin{array}{l}94.7 \pm 1.8^{b} \\
94.5 \pm 1.4^{b}, c \\
94.7 \pm 1.7^{b}\end{array}$ \\
\hline $\begin{array}{l}\text { Tyrode's suspension } \\
50 \times 10^{6} \text { spermatozoa } \\
100 \times 10^{6} \text { spermatozoa } \\
200 \times 10^{6} \text { spermatozoa }\end{array}$ & $\begin{array}{l}95.0 \pm 1.8^{b} \\
95.1 \pm 2.4^{b} \\
95.0 \pm 2.5^{b}\end{array}$ \\
\hline
\end{tabular}

$a_{\text {Mean }} \pm \mathrm{SE}$.

$b, c_{\text {Means }}$ with the same letter are not significantly different. 
recorded for all concentrations of spermatozoa suspended in Tyrode's solution. Neither BSA isolation nor suspending spermatozoa in BSA had a consistent effect on the percentage of spermatozoa with intact acrosomes. Since Lui et al. (1977) reported that the acrosome reaction inducing effectiveness of albumin is dependent upon concentration and purity, it is possible that 38 BSA utilized in the present experiment was not capable of inducing any change in acrosomal integrity, and that ohserved differences in percentage of intact acrosomes were the result of random variability.

Experiment 3. Fertility of Stallion Spermatozoa Isolated in BSA

In the third experiment, 30 Quarter Horse mares were artificially inseminated to compare fertility of spermatozoa isolated in BSA with raw semen diluted with either BSA or Tyrode's solution. Chi-square analysis of the data revealed no significant difference between the pregnancy rate for mares inseminated with isolated spermatozoa compared with control groups inseminated with the same number of live spermatozoa (table 7). Seven of the 10 mares bred with isolated spermatozoa were pregnant after two estrous cycles, while eight of 10 mares became pregnant in each of the control groups. Pregnancy rates in the present experiment are comparable to those reported by 
TABLE 7. PREGNANCY AND FOALING RATE OF MARES INSEMINATED ${ }^{a}$ WITH ISOLATED AND CONTROL SPERMATOZOA

\begin{tabular}{lrrr}
\hline Item & Isolated & Control \\
\hline No. mares/group & 10 & 10 & Tyrode's \\
Total no. pregnant & 7 & 8 & 10 \\
Total no. foaling & 70 & 80 & 8 \\
Males/females & 7 & 6 & 4 \\
\hline
\end{tabular}

$a_{A l l}$ mares inseminated with $100 \times 10^{6}$ live spermatozoa. ${ }^{b}$ Based on rectal palpation at 45 days post-ovulation. 
Hutton and Meacham (1968) for Quarter Horse and Thoroughbred mares.

Although there was no significant difference between the pregnancy rates for mares inseminated with isolated or control spermatozoa, a greater percentage (708) of mares inseminated with isolated spermatozoa foaled compared with mares (60 and 408) inseminated with spermatozoa diluted with BSA and Tyrode's solution, respectively. These percentages are similar to foaling rates of Quarter Horse and Thoroughbred mares reported in the literature (Hutton and Meacham, 1968; Voss et al., 1975).

Sex of the foals produced in this experiment are also presented in table 7. Six of the seven foals produced by insemination of mares with isolated spermatozoa were males, whereas, two of six and three of four foals produced by insemination of mares with spermatozoa diluted with BSA and Tyrode's solution, respectively, were males.

General Discussion

A population of highly motile stallion spermatozoa was isolated in columns of BSA. Modifications of the original procedure of Ericsson et all. (1973) were necessary since preliminary observations showed that BSA concentrations greater than 38 severely impaired the movement of equine spermatozoa. It was also noted that the time interval of 1 hr used in experiments with human and bovine 
spermatozoa was excessively long and appeared to result in exhaustion of stallion spermatozoa. Increases in motility of stallion spermatozoa as a result of the separation procedure are similar to those reported for human (Ericsson et al.., 1973; Glaub et al.., 1976; Glass and Ericsson, 1978) and bovine spermatozoa (Faust et al., 1976, I1lyes et al., 1977). However, studies with human and bovine spermatozoa utilized higher concentrations of BSA (6 to 258) than were utilized in the present study. Also, studies with human and bovine spermatozoa were conducted at room temperature, while results of the present study suggest that greater increases in percent motile spermatozoa are produced by placing the isolation columns in a warm water bath $(36 \mathrm{C})$.

Glaub et al. (1976) and Dmowski et al. (1979a, b) observed that human spermatozoa recovered from the lower BSA fraction of isolation columns exhibited a significantly higher motility score than parent semen samples. Preliminary work with bovine spermatozoa suggests a similar response of spermatozoa of this specie (Faust et al., 1976; Illyes et al.. 1977). Observations with human and bovine spermatozoa, as well as the accelerated progressive motility rate of stallion spermatozoa from the lower BSA fraction in the present study suggest an effect of the isolation procedure beyond a simple physical separation of motile spermatozoa. The possibility exists that exposure of spermatozoa to the 
isolation medium results in a physiological change which has a stimulating effect on progressive motility rate. In support of this hypothesis, Yanagimachi (1970b) reported that hamster epididymal spermatozoa capacitated in vitro in gamma-globulin free human serum were characterized by a sharp increase in rate of motility compared with uncapacitated spermatozoa. Additional studies (Lutwak-Mann, 1954; Caravaglios and Cilotti, 1957) indicate that blood serum and follicular fluid are similar and that the fraction in mammalian follicular fluid which has the capability of inducing the acrosome reaction in hamster and rabbit spermatozoa is serum albumin (Lui et al.. 1977; Oliphant et al.. 1977). In vitro capacitation of spermatozoa from the hamster (Barros and Garavagno, 1970; Yanagimachi, 1970a; Bavister, 1973), mouse (Miyamoto and Chang, 1973), guinea pig (Yanagimachi and Usui, 1974) and rat (Toyoda and Chang, 1974); Davis, 1976) is apparently achieved when serum albumin is included in the culture media; also, follicular fluid has been utilized to induce in vitro capacitation of hamster (Barros and Austin, 1967; Yanagimachi, 1969a, b), mouse (Iwamatsu and Chang, 1969) and bovine spermatozoa Breuer and Wells, 1977). Therefore, a possible explanation for the accelerated progressive motility rate of stallion spermatozoa isolated in the lower BSA fraction is the initiation of capacitation. Ericsson (1967a, b) concluded that T-HCl was bound to a substance 
which coats mammalian spermatozoa and is removed with this substance as spermatozoa undergo capacitation. Since capacitation in the rabbit requires 10 to $11 \mathrm{hr}$ in the Fallopian tube or estrous uterus of rabbit does and T-HCI was lost from spermatozoa in these sites within 2 hr, Vaidya et al. (1969) concluded that removal of T-HCl from spermatozoa was not a visible concomitant of functional capacitation. It was further noted that the time when T-HCl was removed may correspond to the time of initiation of capacitation.

Since centrifugation reduces the viability of stallion spermatozoa, modifications of the technique of Ericsson (1967a, b) were necessary in the present study. Excess T-HCl and seminal plasma were not separated from labelled spermatozoa. However, BSA isolation effectively removed T-HCl from spermatozoa and fluorescent scores for spermatozoa suspended in BSA were significantly lower than the initial score and the fluorescent score for spermatozoa in the top semen layer of the isolation columns. These results suggest that BSA may alter the bonding of $\mathrm{T}-\mathrm{HCl}$ to the sperm cell surface. Byrd et al. (1979) reported that the mean time interval for removal of $\mathrm{T}-\mathrm{HCl}$ from bovine spermatozoa decreased with increasing bSA concentrations. since findings of previous workers as well as results of the present study suggest that $\mathrm{T}-\mathrm{HCl}$ removal involves a reaction other than simple physical "washing off" this 
reaction may constitute the initiation of capacitation of equine spermatozoa.

Acrosomal integrity of spermatozoa has been utilized by some researchers as an indicator of capacitation. Although Bedford (1963) reported that there was no morphological alteration of rabbit spermatozoa during capacitation, Austin and Bishop (1958) and Yanagimachi and Noda (1970) observed that capacitation of hamster spermatozoa involves both acrosomal and postnuclear cap surface changes. In the present experiment, the percentage of spermatozoa with intact acrosomes was similar for all treatments thus indicating that neither BSA isolation nor dilution in BSA affect the acrosomal integrity of stallion spermatozoa. However, since Miyamoto and Chang (1973) reported that mouse spermatozoa required $2 \mathrm{hr}$ to undergo in vitro capacitation in medium containing serum albumin, it is possible that the $30 \mathrm{~min}$ isolation period in the present experiment may have been too short to affect the acrosomal integrity of stallion spermatozoa.

In the third experiment, fertility of isolated spermatozoa were compared with spermatozoa diluted with BSA or Tyrode's solution. Numerous studies (Pickett and Voss, 1972; Pickett and Voss, 1975; Demick et a1., 1976) have ghown that pregnancy rates for mares inseminated with $500 \times 10^{6}$ or $100 \times 10^{6}$ live spermatozoa are similar. Furthermore, Pace and Sullivan (1975) reported that 
foaling rates were improved $(P<.05)$ by increasing the number of motile spermatozoa insemination from $40 \times 10^{6}$ to $80 \times 10^{6}$, but was not further improved by increasing the number to $160 \times 10^{6}$ motile spermatozoa. More recently, Allen et al. (1976) recommended that a minimum of $100 \times 10^{6}$ live spermatozoa be used for $A I$ in the mare. In view of these findings, the suggested minimum number of live spermatozoa were used in the present experiment in an attempt to increase the chances of detecting any possible differences in fertility between isolated and control spermatozoa. Although results of this study revealed no advantage in fertility in favor of isolated spermatozoa, the higher foaling rate of mares inseminated with isolated spermatozoa compared with control spermatozoa is encouraging. Since the health and vigor of these foals was not different. from foals produced by control inseminations, there does not seem to be any detrimental effects associated with spermatozoa isolated in BSA. Also, the number of male foals produced by mares inseminated with isolated spermatozoa suggests a possible alteration of the sex ratio. However, since a relatively small number of mares was inseminated in this experiment, it would be premature to draw any conclusions regarding the semen sexing capabilities of the isolation procedure.

Results of this study confirm that a population of highly motile spermatozoa, free of debris and abnormal 
spermatozoa, can be isolated from stallion semen. spermatozoa isolated in BSA or diluted with BSA are characterized by a marked increase in progressive rate, possibly due to the initiation of sperm cell capacitation. Since daily heat checking and palpation of the ovaries permits insemination at a time which coincides with ovulation, insemination of mares with capacitated spermatozoa could possibly inprove conception rates. Fertility may also be enhanced by insemination of mares with a population of highly motile morphologically normal spermatozoa. of secondary importance, these results as well as those in the human suggest the possibility of altering sex ratios. Additional studies are warranted to further evaluate the fertility of isolated spermatozoa, the possibility of sex control in horses and to determine the feasibility of utilizing BSA as a diluent for extending stallion semen. Also, further studies are suggested to determine if BSA isolation is capable of inducing in vitro capacitation of equine spermatozoa. 
CHAPTER V

SUMMARY

In an initial experiment, semen from three mature stallions was used in an attempt to isolate a population of highly motile spermatozoa. An ejaculate of semen was collected from each stallion with an artificial vagina at 7-day intervals for 35 days. Following collection, semen was evaluated for percent motile spermatozoa and rate of progressive motility (scale 1 to 4 ). Two ml of semen were layered over $6 \mathrm{ml}$ of 38 bovine serum albumin (BSA) in $13 x$ $125 \mathrm{~mm}$ columns at room temperature (RMT) or in a warm water bath (WB). Immediately after collection the mean value for percent motile spermatozoa was 41.7 . Following a 30 min isolation period, the top layer and upper and lower halves of the BSA fraction were separately withdrawn from columns and reevaluated. In both the RMT and WB isolation columns, percent motile spermatozoa decreased in the top semen fraction when compared with the initial estimate. Percent motile spermatozoa in the lower BSA fraction increased $(P<.01)$ to 58.7 and 65.7 in the RMT and WB columns, respectively. Also, there was a 27.18 increase $(P<.01)$ in motile spermatozoa in the upper BSA fraction for the wB treatment.

Rate of progressive motility showed significant changes following isolation of spermatozoa in BSA. Although there was no change in progressive rate of 
spermatozoa from the upper BSA fraction of the RMT columns, progressive rate of spermatozoa from the lower BSA fraction increased $(\mathrm{P}<.05)$ to 3.3. Also, progressive motility rate of spermatozoa from the upper and lower BSA fractions of the WB columns increased $(P<.01)$ to 3.5 and 3.7 , respectively.

In a second experiment, a total of 40 ejaculates from four mature stallions was utilized to determine the effects of BSA isolation on removal of a supravital stain, Tetracycline hydrochloride (T-HCl), and on the acrosomal integrity of spermatozoa. Based on a scale 0 to 4 , the initial fluorescent score of spermatozoa labelled with T-HCl was 3.9. Following BSA isolation, the fluorescent scores of spermatozoa in the top semen layer and upper and lower halves of the BSA fractions decreased $(P<.05)$ to 3.0 , 0.9 and 0.7 , respectively. Also, there was a significant decrease in fluorescence of spermatozoa $(50,100$ and $200 x$ $10^{6}$, spermatomoa suspended in 38 BSA compared with the initial value. Fluorescence of 50 and $100 \times 10^{6}$ spermatozoa was similar; however, fluorescent scores of 50 and $100 \times 10^{6}$ spermatozoa were significantly lower than scores for $200 \times 10^{6}$ spermatozoa. These results indicate the migration of spermatozoa through BSA effectively removes $\mathrm{T}-\mathrm{HCl}$ and that concentration of spermatozoa may influence the removal of this supravital stain. Although fluorescent scores for spermatozoa suspended in Tyrode's 
solution were lower than initial values. Tyrode's spermatozoa had a higher fluorescent score than spermatozoa suspended in BSA; thus indicating an effect of BSA beyond a simple physical removal by suspension in a medium.

The percentage of intact acrosomes of spermatozoa was similar for all treatments. However, spermatozoa in the lower fractions of BSA isolation had fewer $(P<.05)$ intact acrosomes than spermatozoa in BSA (50 and $200 \times 10^{6}$ ) in Tyrode's solution. Since the percentage of intact acrosomes in the lower BSA fraction was not different from values recorded for the top semen layer, upper BSA fraction, $100 \times 10^{6}$ spermatozoa in BSA, and the initial values, it appears that differences in the percentage of intact acrosomes in the present experiment were due to random variability and cannot be logically explained from these data.

In a third experiment, 30 Quarter Horse mares were inseminated to compare the fertility of spermatozoa isolated in BSA with raw semen diluted with each of the constituents of the isolation mediun, i.e.. BSA and Tyrode's solution. There was no significant difference between the pregnancy rates for 10 mares inseminated with $100 \times 10^{6}$ live spermatozoa isolated in BSA and that of control mares inseminated with the same number of live spermatozoa. Although, results of this study revealed no advantage in fertility in favor of isolated spermatozoa, a 
higher foaling rate was recorded for mares inseminated with isolated spermatozoa. Also, six of seven foals produced by insemination of mares isolated spermatozoa were males, whereas, two of $s i x$ and three of four foals produced by insemination of mares with spermatozoa diluted with BSA and Tyrode's solution, respectively, were males. 


\section{CHAPTER VI}

CONCLUSIONS

The results of the present study warrant the following conclusions :

1. Layering of stallion spermatozoa over columns of BSA results in the isolation of a population of spermatozoa which has a higher percentage of motile spermatozoa and a faster progressive rate than the parent semen sample.

2. Removal of tetracycline hydrochloride during isolation in BSA suggests an action of the isolation medium beyond the simple physical "washing off" of this supravital stain, possibly the initiation of capacitation.

3. The integrity of sperm cell acrosomes is not affected by isolation of spermatozoa in BSA or by dilution of spermatozoa in BSA.

4. Reproductive efficiency of mares is not affected by insemination of isolated spermatozoa; however, mares inseminated with isolated spermatozoa had a higher foaling rate than control mares.

5. More males were produced by mares inseminated with isolated spermatozoa; however, the small number of mares inseminated in the present experiment restricts any further conclusion regarding the use 
of isolated spermatozoa to control the sex of foals. 
APPENDIX 
APPENDIX TABLE 1. ANALYSIS OF VARIANCE FOR EFFECT OF BSA ISOLATION ON PERCENT MOTILE SPERMATOZOA IN EXPERIMENT 1

\begin{tabular}{lcc}
\hline \multicolumn{1}{c}{ Source } & df & Mean square \\
Horse & 2 & 4200.18 \\
Week & 4 & 178.98 \\
Horse x week & 8 & 456.90 \\
Treatment & 2 & $15261.29^{a}$ \\
Position & 2 & $5325.74^{\mathrm{a}}$ \\
Treatment $x$ position & 4 & $1299.63^{\mathrm{a}}$ \\
Residual & 112 & 42.75 \\
\hline
\end{tabular}

$$
a_{p}<.01
$$


APPENDIX TABLE 2. ANALYSIS OF VARIANCE FOR EFFECT OF BSA ISOLATION ON PROGRESSIVE MOTILITY RATE OF SPERMATOZOA IN EXPERIMENT 1

\begin{tabular}{lcc}
\hline \multicolumn{1}{c}{ Source } & df & Mean square \\
\hline Horse & 2 & 756.30 \\
Week & 4 & 34.44 \\
Horse $x$ week & 8 & 93.33 \\
Treatment & 2 & $3027.41^{\mathrm{a}}$ \\
Position & 2 & $678.52^{\mathrm{a}}$ \\
Treatment $x$ position & 4 & $118.51^{\mathrm{a}}$ \\
Residual & 112 & 19.07 \\
\hline
\end{tabular}

$a_{p}<.01$. 
APPENDIX TABLE 3. ANALYSIS OF VARIANCE FOR EFFECT OF BSA ISOLATION, BSA AND TYRODE'S SOLUTION ON PERCENT MOTILE SPERMATOZOA IN EXPERIMENT 2

\begin{tabular}{lcc}
\hline Source & df & Mean square \\
Ejaculate & 39 & $587.56^{\mathrm{a}}$ \\
Combination & 9 & $7978.22^{\mathrm{a}}$ \\
Error & 351 & 35.15 \\
\hline
\end{tabular}

$a_{P}<.01$

APPENDIX TABLE 4. ANALYSIS OF VARIANCE FOR EFFECT OF BSA ISOLATION, BSA AND TYRODE'S SOLUTION ON PROGRESSIVE MOTILITY RATE OF SPERMATOZOA IN EXPERIMENT 2

\begin{tabular}{lcc}
\hline Source & df & Mean square \\
\hline Ejaculate & 39 & $178.78^{\mathrm{a}}$ \\
Combination & 9 & $794.78^{\mathrm{a}}$ \\
Error & 351 & 13.82 \\
\hline
\end{tabular}

$a_{p}<.01$ 
APPENDIX TABLE 5. ANALYSIS OF VARIANCE FOR EFFECT OF BSA ISOLATION, BSA AND TYRODE'S SOLUTION ON FLUORESCENCE OF SPERMATOZOA IN EXPERIMENT 2

\begin{tabular}{|c|c|c|}
\hline Source & $d f$ & Mean square \\
\hline Ejaculate & 39 & $0.54^{a}$ \\
\hline Combination & 9 & $41.01^{a}$ \\
\hline Error & 351 & 0.27 \\
\hline
\end{tabular}

$$
a_{P}<.01
$$

APPENDIX TABLE 6. ANALYSIS OF VARIANCE FOR EFFECT OF BSA ISOLATION, BSA AND TYRODE'S SOLUTION ON PERCENTAGE OF SPERMATOZOA WITH INTACT ACROSOMES IN EXPERIMENT 2

\begin{tabular}{lcc}
\hline \multicolumn{1}{c}{ Source } & df & Mean square \\
Ejaculate & 39 & $16.12^{\mathrm{b}}$ \\
Combination & 9 & $6.13^{\mathrm{a}}$ \\
Error & 351 & 2.90 \\
\hline
\end{tabular}

$$
\begin{aligned}
& \mathbf{a}_{\mathrm{P}}<.05 \\
& \mathbf{b}_{\mathrm{P}}<.01
\end{aligned}
$$




\section{LITERATURE CITED}

Allen, W. R., J. M. Bowen, C. J. Frank, L. M. Jeffcott and P. D. Rossdale. 1976. The current position on $A I$ in horse breeding. Equine Vet. J. 8:72.

Almquist, J. O. 1951. A comparison of penicillan, streptomycin and sulfanilamide for improving the fertility of semen from bulls of low fertility. J. Dairy Sci. $34: 819$.

Anderson, J. 1941. Further investigations on the semen of the bull. Vet. Rec. 53:198.

Austin, C. R. 1951. Observations on the penetration of the sperm into the mamulian egg. Aust. J. Sci. Res. (B) $4: 581$.

Austin, C. R. 1967. Capacitation of spermatozoa. Internat'1. J. Fertil. $12: 25$.

Austin, C. R. and M. W. H. Bishop. 1958, Role of the rodent acrosome and perforatorium in fertilization. Proc. RoY. SOC. (B) 149:234.

Back, D. G., B. W. Pickett, J. L. Voss and G. E. Seidel. 1975. Effect of antibacterial agents on the motility of stallion spermatozoa at various storage times, temperature and dilution rates. J. Anim. Sci. 41:137.

Ballinger, H. I. 1970. The effect of inseminations carried out early or late in oestrus on the sex ratio of calves born. vet. Rec. 86:631.

Bangham, A. D. 1961. Electrophoretic characteristics of ram and rabbit spermatozoa. Proc. Roy. Soc. (B) 155 : 292.

Barros, C. and C. R. Austin. 1967. In vitro fertilization and sperm acrosome reaction in the hamster. J. Exp. zoo1. $166: 317$.

Barros, C., M. Berrios and E. Herrera. 1973. Capacitation in vitro of guinea pig spermatozoa in a saline solution. J. Reprod. Fertil. 34:547.

Barros, C. and A. Garavagno. 1970. Capacitation of hamster spermatozoa with blood sera. J. Reprod. Fertil. 22: 381 . 
Bavister, B. D. 1973. Capacitation of golden hamster spermatozoa during incubation in culture medium. $\mathrm{J}$. Reprod. Fertil. 35:161.

Beck, K. J., S. Herschel, R. Hungershofer and E. Schwinger. 1976. The effect of steroid hormones on motility and selective migration of $X$ - and $Y$-bearing human spermatozoa. Fertil. and steril. 27:407.

Bedford, J. M. 1963. Morphological reaction of spermatozoa in the female reproductive tract of the rabbit. J. Reprod. Fertil. 6:245.

Bedford, J. M. 1970. Sperm capacitation and fertilization in mammals. Biol. Reprod. (Suppl.) 2:128.

Bedford, J. M. and A. M. Bibeau. 1967. Failure of sperm sedimentation to influence the sex ratio of rabbits. J . Reprod. Fertil. 14:167.

Bennett, D. and E. A. Boyse. 1973. Sex ratio in progeny of mice inseminated with sperm treated with $\mathrm{H}^{-} \mathrm{Y}$ antiserum. Nature 246:308.

Bhattacharya, B. C. 1962. The different sedimentation ratio of $X-$ and $Y-s p e r m a t o z o a$ and the question of sex ratio. Anim. Breed. Abstr. 30. No. 2958.

Bhattacharya, B. C., A. D. Bangham, R. V. Cro and R. D. Keynes. 1966. An attempt to predetermine the sex of calves by artificial insemination with spermatozoa separated by sedimentation. Nature 211:863.

Bielanski, w. 1951. Characteristics of the semen of stalions. Mem. Acad. Pol. Sci. No. 16.

Bielanski, W. 1975. The evaluation of stallion semen in aspects of fertility control and its use for artificial insemination. J. Reprod. Fertil. (Suppl.) 23: 19.

Bishop, D. W. and H. D. Mathews. 1952. The significance of intravas $\mathrm{pH}$ in relation to sperm motility. Science 115:209.

Bishop, M. W. H., R. C. Campbe11, J. C. Hancock and A. Walton. 1954. Semen characteristics and fertility in the bull. J. Agr. Sci. 44:227.

Black, V. B., V. C. Peduto and E. V. Servy. 1978. Male factor infertility treated by isolation of progressively motile sperm. Fertil. and Steril. 29:241 (Abstr.). 
Blandau, R. J. and E. S. Jordan. 1941. The effect of delayed fertilization on the development of the rat ovum. Amer. J. Anat. 68:275.

Blom, E. and A. Birch-Anderson. 1962. Ultrastructure of sterilizing "knobbed acrosome" defect in the bull. Nature 194:989.

Bowen, J. M. 1969. Artificial insemination in the horse. Equine Vet. J. 1:98.

Brever, D. J. and M. E. Wells. 1977. Effects of in vitro incubation of bovine spermatozoa in bovine follicular fluid. J. Anim. Sci. 44:262.

Buckner, P. J., E. I. Willett and N, Bayley, 1954. Laboratory tests, singly and in combination, for evaluating fertility of semen and of bulls. J. Dairy Sci. $37: 1050$.

Burkov, I. A. 1971. The effects of immunization of rabbits with cock semen on the sex of the progeny. Anim. Breed. Abstr. 39. No. 2336.

Buttle, H. R. L. and J, L. Hancock. 1965. Sterile boars with "knobbed spermatozoa". J. Agr. Sci. 65:255.

Byrd, E. W., L. L. Goodeaux, S. H. Pool and R. A. Godke. 1979. Effect of bovine serum albumin and $\mathrm{Ca}^{++}$on capacitation of bovine spermatozoa. Theriogenol. $11: 93$ (Abstr.).

Caravaglios, R. and R. Cilotti. 1957. A study of the proteins in follicular fluid of the cow. J. Endocrinol. $15: 273$.

Cascieri, M., R. D. Amann and R. H. Hammarstedt. 1976. Adenine nucleotide changes at initiation of bull sperm motility. J. Biol. Chem. 251:787.

Casida, L. E. and R. I. Murphee, 1942. Fertility and sex ratio in the rabbit. J. Hered. 33:434.

Chandler, J.E., R. L. Nebel, R. W. Adkinson and A. Baham. 1978. The efficiency of multiple seminal quality tests in predicting field bull fertility. J. Anim. Sci. (Suppl.) 46:339 (Abstr.).

Chang, M. L. 1951. Fertilizing capacity of spermatozoa deposited into the Fallopian tubes. Nature 168:697.

Cheng, P., L. E. Casida and G. R. Barrett. 1949. Effects of dilution on motility of bull spermatozoa and the 
relationship between motility in high dilution and fertility. J. Anim. Sci. 8:81.

Cohen, M. R. 1967. Differentiation of sex as determined by ovulation time. Intern'l. J. Fertil. 12:32.

Cole, L. J., E. Waletzky and M. Shackelford. 1940. A test of sex control by modification of the acid-alkaline balance. J. Hered. 31:501.

Cupps, P. T., R. C. Laben and S. W. Meal, 1953, The relation of certain semen quality tests to breeding efficiency and characteristics of semen from low fertility bulls before and after hormone injection. J. Dairy Sci. 36:422.

David, G., C. Jeulin, A. Boyce and D. Schwartz. 1977. Motility and percentage of $Y$ - and YY-bearing spermatozoa in human semen samples after passage through bovine serum albumin. J. Reprod. Fertil. 50:377.

Davis, B. K. 1976. Influence of serum albumin on the fertilizing ability in vitro of rat spermatozoa. Proc. Soc. Exp. Biol. Med. 151:240.

Day, F. T. 1940. The stallion and fertility. Vet. Rec. $52: 996$.

Demick, D. C., J. L. Voss, and B. W. Pickett. 1976. Effect of cooling, storage, glycerolization and spermatozoal numbers on equine fertility. J. Anim. Sci. $43: 633$.

Diasio, R. B. and R. H. Glass. 1971. Effects of pH on the migration of $X$ and $Y$ sperm. Fertil. and Steril, 22: 203 .

Dmowski, W. P., L. Gaynor, R. Rao, M. Lawrence and A. Scommegna. 1979a. Artificial insemination with oligospermic semen separated on albumin columns. Fertil. and steril. 31:58.

Dmowski, W. P., L. Gaynor, R. Rao, M. Lawrence and A. Scomnegna. 1979b. Use of albumin gradients for $X$ and $Y$ sperm separation and clinical experience with male sex preselection. Fertil. and steril. 31:52.

Donald, H. P. and J. L. Hancock. 1953. Evidence of gene controlled sterility in bulls. J. Agr. Sci. 43:178.

Dott, H. M. 1975. Morphology of stallion spermatozoa. J. Reprod. Fertil. (Suppl.) 23:41. 
Douglas, D. C., D. O. Black, W. H. Carey and D. L. Delahantz. 1976. The effect of ion-exchange column chromatography on separation of $X$ and $Y$ chromosome bearing human spermatozoa. Fertil. and steril. 27: 1187 .

Ericsson, R. J. 1967a. A fluorometric method for measurement of sperm capacitation. Proc. Soc. Exp. Biol. Med. 125:1115.

Ericsson, R. J. 1967b. Technology, physiology and morphology of spermatozoa capacitation. J. Reprod. Fertil. (Suppl.) 2:65.

Ericsson, R. J. 1977. Isolation and storage of progressively motile human sperm. Andrologia 9:111.

Ericsson, R. J, C. N. Langevin and M. Nishino. 1973 . Isolation of fractions rich in human $Y$ sperm. Nature 246:421.

Ericsson, R. J. and R. H. Glass. 1977. Isolation of progressively motile sperm from infertile men. Fertil. and Steril. 28:330 (Abstr.).

Ericsson, R. J. and V. F. Baker. 1967. Binding of tetracycline to mammalian spermatozoa. Nature 214:403.

Evans, J.M., T. A. Douglas and J. P. Renton. 1975. Attempt to separate fractions $r i c h$ in human $Y$ sperm. Nature 253:352.

Faust, A. M., J. L. Kreider, R. J. Ericsson, S. D. Goodeaux and R. A. Godke. 1976. Isolation of progressively motile spermatozoa from bull semen. J. Anim. Sci. $43: 283$ (Abstr.).

Foote, R. H. 1977. Sex ratio in dairy cattle under various conditions. Theriogenol. 8:349.

Foote, R. H. and R. W. Bratton. 1950. The fertility of bovine semen in extenders containing sulfanilamide, penicillan, streptomycin and polymyxin. J. Dairy Sci. $33: 544$.

Foote, R. H. and P. Miller. 1971. What sex ratio control might mean in the animal world? In C. A. Kiddy and H. D. Hafs (Ed.) Sex Ratio at Birth-Prospects for Control. Aner. Soc. Anim. Sci., Champaign, Illinois.

Gardner, K. E. 1950. The sex ratio in calves resulting from artificial insemination. J. Dairy Sci. 33:391 (Abstr.). 
Glass, R. H. and R. J. Ericsson. 1978. Intrauterine insemination of isolated motile sperm. Fertil. and steril. $29: 535$.

Glaub, J. C., R. L. Mills and D. F. Katz. 1976. Improved motility recovery of human spermatozoa after freeze preservation via a new approach. Fertil. and steril. $27: 1283$.

Gordon, M. J. 1957. Control of sex ratio in rabbits by electrophoresis of spermatozoa. Proc. Nat. Acad. Sci. 43:913.

Gray, J. 1928. The effect of dilution on the activity of spermatozoa. J. Exp. Biol. 5:337.

Haag, F. M. 1959. Evaluation of "dismount" semen in thoroughbred horse breeding. J. Amer. Vet. Med. Ass. $134: 312$.

Hafs, H. D. and L. J. Boyd. 1971. Galvanic separation of $X$ - and $Y$-chromosome bearing sperm. In Sex Ratio

at Birth-Prospects for Control, Amer. Soc. Anim. Sci., Champaign, Tllinois, p. 85.

Hafs, H. D. and L. J. Boyd. 1974. Sex ratio of calves from insemination after electrophoresis sperm. J. Anim. Sci. 38:603.

Hahn, E. W. and R. L. Hays. 1963. Modifications of the secondary sex ratio in albino rats by progesterone and oestrogen therapy. J. Reprod. Fertil. 6:409.

Hammond, J. 1934. Fertilization of rabbit ova in relation to time. Brit. J. Exp. Biol. 11:140.

Hancock, J. L. 1949. Evidence of an inherited seminal character associated with infertility of Friesian bul1s. Vet. Rec. 61:308.

Hancock, J. L. 1952. The morphology of bull spermatozoa. J. Exp. Biol. 29:445.

Hancock, J. L. 1953. The spermatozoa of sterile bulls. J. Exp. Biol. 30:50.

Hancock, R. J. T. 1978. Comparison of effects of normal rabbit sera and anti-cock sperm sera on rabbit sperm, including comparison of effects on the sex ratio. Biol. Reprod. 18:510.

Harcenko, P. A. 1967. An investigation of the effect of the treatment of spermatozoa with androgens on the sex ratio among the progeny of pigs. Anim. Breed. Abstr. 36. No. 1724 . 
Harrison, R. A. P., H. M. Dott and G. C. Foster. 1978 . Effect of ionic strength, serum albumin and other macromolecules on the maintenance of motility and the surface of mammalian spermatozoa in a simple medium. J. Reprod. Fertil. 52:65.

Hart, D. and J. D. Moody. 1949. Sex ratio: experimental studies demonstrating controlled variations. Ann. surgery. 129:550.

Harvey, E. N. 1946. Can the sex of mammalian offspring be controlled? J. Hered. 37:71.

Hutton, C. A. and T. N. Meacham. 1968. Reproductive efficiency on fourteen horse farms. J. Anim. Sci. $27: 434$.

Illyes, D. R., W. R. Warren, A. Baham, J. L. Kreider, and R. A. Godke. 1977. Freezing separated bovine spermatozoa. J. Anim. Sci. (Suppl. 1) 45:471.

Iwamatsu, T. and M. C. Chang. 1969. In vitro fertilization of mouse eggs in the presence of bovine follicular fluid. Nature 224:919.

Iype, P. T., K. A. Abraham and P. M. Bhargava. 1963. Further evidence for a positive role of the acrosome in the uptake of labelled amino acids by bovine and avian spermatozoa. J. Reprod. Fertil. 5:151.

Kiddy, C. A. and L. F. Bailey. 1973. Sex ratios in rabbits from semen subjected to altered atmospheric pressure. J. Anim. Sci. 37:768.

Kleegman, S. 1954. Therapeutic donor insemination. Fertil. and Steril. 5:7.

Knaack, J. 1970. Artificial control of sex with sedimented bull spermatozoa. Anim. Breed. Abstr. 38. No. 3591.

Knodt, C. B. and G. W. Salisbury. 1946. The effect of sulfanilamide upon the livability and metabolism of bovine spermatozoa. J. Dairy Sci. 29:285.

Koltzoff, N. K. and V. N. Schroder. 1933. Artificial control of sex in the progeny of mammals. Nature 131: 329 .

Krzanowski, M. 1970. Dependence of primary and secondary sex ratio on the rapidity of sedimentation of bull semen. J. Reprod. Fertil. 23:11.

Lasley, J.F. 1951. Spermatozoan motility as a measure of semen quality. J. Anim. Sci. 10:211. 
Lewin, S. 1956. Artificial sex regulation of mammalian offspring. Brit. Vet. J. 112:549.

Lindahl, P. E. 1956. Counter-streaming centrifugation of bull spermatozoa. Nature 178:491.

Lindahl, P. E. 1958. Separation of bull spermatozoa carrying $X$ - and $Y$-chromosomes by counter-streaming centrifugation. Acta Agr. Scand 8:226.

Ludwick, T. M., D. Olds and M. Carpenter. 1948. A method of evaluating bull semen. J. Dairy Sci. 31:677

(Abstr.).

Lui, C. W., L. E. Cornett and S. Meizel. 1977. Identification of the bovine follicular fluid protein involved in the in vitro induction of the hamster sperm acrosome reaction. Biol. Reprod. 17:34.

Lui, C. W. and S. Meizel, 1977. Biochemical studies of in vitro acrosome reaction inducing activity of bovine serum albumin. Differentiation 9:59.

Lutwak-Mann, C. 1954. Note on the chemical composition of bovine follicular fluid. J.Agr. Sci. 44:477.

Mann, T. 1954. The Biochemistry of Semen. John Wiley and Sons, Inc. New York.

Mann, T., C. S. Minotakis and C. Polge. 1963. Semen composition and metabolism in the stallion and jackass. J. Reprod. Fertil. 5:109.

Margolin, S., J. W. Bartlett and O. L. Lepard. 1943. The relation of longevity to fertility of bull semen. $J$. Dairy Sci. 26:983.

Mckenzie, F. F. and R. W. Phillips. 1934. Measuring fertility in the ram. J. Amer. Vet. Med. Ass. 84:189.

McPhee, H. C. and O. N. Eaton. 1942. Experimental attempts to modify the sex ratio. J. Hered. 33:429.

Miyamato, H. and M. C. Chang. 1973. The importance of serum albumin and metabolic intermediates for capacitation of spermatozoa and fertilization of mouse eggs in vitro. $J$. Reprod. Fertil. 32:193.

More O'Farrall, G. H., T. N. Meacham and W. E. Foreman. 1968. Attempts to separate rabbit spermatozoa by means of froth flotation and the sex ratio of offspring born. J. Reprod. Fertil. 16:243. 
Morton, B., J. Lum-Harrigan, L. Albagli, J. Looss. 1974. The activation of motility in quiescent hamster sperm from the epididymis by calcium and cyclic nucleotides. Biochem. Biophys. Res. Comm, 56:372.

Morton, B. E., R. Sagadraca, C. Fraser. 1978. Sperm motility within the mammalian epididymis: Species variation and correlation with free calcium levels in epididymal plasma. Fertil. and Steril, 26:695.

Mudd, S., E. B. H. Mudd and A. Keltch. 1929. The specificity of mammalian spermatozoa with special reference to electrophoresis as a means of serological differentiation. J. immunol. 17:39.

Nishikawa, Y. 1975. Studies on the preservation of $r$ aw and frozen horse semen. J. Reprod. Fertil. (Suppl.) $23: 99$.

O1iphant, G., C. L. Cabot and C. A. Singhas. 1977. Nature of the rabbit acrosome reaction-inducing activity of follicular fluid. J. Reprod. Fertil. 50:245.

Oresnik, A. 1970. The specific gravity of spermatozoa of different domestic animals and its relationship to the sex specificity of the spermatozoa. Anim. Breed. Abstr. 38. No. 45 .

Pace, M. M. and J. J. Sullivan. 1975. Effect of timing of insemination, numbers of spermatozoa and extender components on the pregnancy rate in mares inseminated with frozen semen. J. Reprod. Fertil. (Suppl.) 23:115.

Petrenko, I. P. 1968. Differentiation of spermatozoa of the ram (Ovis aries) by sedimentation and sex ratio among the progeny. Anim. Breed. Abstr. 36 . No. 3759 .

Petrenko, I. P. and I. V. Tkackuk. 1970. Incubation of semen of farm animals with androgens and sex ratio of the progeny after artificial insemination. Anim. Breed. Abstr. 40. No. 1324 .

Pickett, B. W., L. D. Burwash, J. L. Voss and D. B. Back. 1975. Effect of seminal extenders on equine fertility. J. Anim. Sci. 40:1136.

Pickett, B. W. and J. L. Voss. 1972. Reproductive management of the stallion. Proc. 18 th Annu. Conv. Amer. Ass. Equine Prac. p. 501.

Pickett, B. W. and J. L. Voss. 1975. The effect of semen extenders and sperm numbers on mare fertility. J. Reprod. (Suppl.) 23:95. 
Quisenberry, J.H. and $S$. V. Chandiramani. 1940. An experimental attempt to modify the sex ratio in rats and rabbits. J. Hered. 31:503.

Rhode, W., T. Porstmann, S. Prehn and G. Dorner. 1975. Gravitational pattern of the $Y$-bearing human spermatozoa in density gradient centrifugation. $J$. Reprod. Ferti1. $42: 587$.

Rob, O. and J. Rozenik. 1976. Study of testicular morphology and sperm ultrastructure from bulls with disturbed spermiogenesis and Bedsonia infection. VIII Intern'l. Cong. Anim. Reprod. and A. I. 4:746.

Roberts, E. 1940. The effect of lactic acid and sodium bicarbonate on the sex ratio. J. Hered. 31:499.

Rollinson, D. H. L. and J. B. Makinson. 1949. Evidence of an inherited seminal character associated with infertility of Friesian bul1s. Vet. Rec. 61:373.

Ross, A., J. A. Robinson and H. J. Evans. 1975. Failure to confirm separation of $X$ - and $Y$-bearing human sperm using BSA gradients. Nature 253:354.

Roussel, J. D., J. N. Thomas, T. E. Patrick and L. F. Gomila. 1972. Parallelism between acrosomal morphology and other semen characteristics with betaglucuronidase activity and freezability. 69 Ann. Meet. Ass. Southern Ag. Workers, Richmond.

Saacke, R. G., R. P. Amann and C. E. Marshall. 1968. Acrosomal cap abnormalities of sperm from subfertile bul1s. J. Anim. Sci. 27:1391.

Saacke, R. G. and C. E. Marshall. 1968. Observations on the acrosomal cap of fixed and unfixed bovine spermatozoa. J. Reprod. Fertil. 16:511.

Schilling, E. 1966. Experiments in sedimentation and centrifugation of bull spermatozoa and the sex ratio of born calves. J. Reprod. Fertil. 11:469.

Schilling, E. and D. Thomahlen. 1976. Attempts for separation of $X$ - and $Y$-spermatozoa by density gradient centrifugation. VIII Intern'1. Cong. Anim. Reprod. and A. I. P. 931 .

Sevine, A. 1968. Experiments on sex control by electrophoretic separation of spermatozoa in the rabbit. J. Reprod. Fertil. 16:7. 
Shastry, P. R., U. Hedge and S. A. Rao. 1977. Use of ficol1-sodium metrizoate density gradient to separate human $X$ - and $Y$-bearing spermatozoa. Nature 269:58.

Soupart, P. 1975. MGA-m appearance in ejaculated human sperm. Abstr. 8th Annu. Meet. Soc. for study of Reprod. P. 120 .

Stambaugh, R. and J. Buckley. 1971. Association of the lactic dehydrogenase $x_{4}$ isozyme with male-producing rabbit spermatozoa. J. Reprod. Fertil. 25:275.

Steel, R. G. D. and J. H. Torrie. 1960. Principles and Procedures of statistics. McGraw-Hill Book Co., New York.

Storey, B. T. 1975. Energy metabolism of spermatozoa. IV. Effect of calcium ion on respiration of mature epididymal sperm of the rabbit. Biol. Reprod. 13:1.

Sumner, A. T. and J. A. Robinson. 1976. A difference in dry mass between heads of $X-$ and $Y$-bearing human spermatozoa. J. Reprod. Fertil. 48:9.

Suter, D., P. Y. W. Chow and I. C. A. Martin. 1979. Maintenance of motility in human spermatozoa by energy derived through oxidative phosphorylation and addition of albumin. Biol. Reprod. 20:505.

Swanson, E. W. and H. A. Herman. 1941. Variations in bull semen and their relation to fertility. J. Dairy Sci. $24: 321$.

Swanson, E. W. and H. A. Herman. 1944. The correlation between some characteristics of dairy bull semen and conception rate. J. Dairy Sci. 27:297.

Teunissen, G. H. B. 1946. An abnormality of the acrosome in the spermatozoa of a bull. Anim. Breed. Abstr. $15: 34$.

Toyoda, Y. and M. C. Chang. 1974. Fertilization of rat eggs in vitro by epididymal spermatozoa and the development of the eggs following transfer. J. Reprod. Fertil. 36:9.

Trimberger, G. W. and H. P. Davis. 1942. The relation of morphology to fertility in bull semen. J. Dairy Sci. $25: 692$ (Abstr.).

Turner, T. T., D. D'Addario and S. S. Howards. 1978. Further observations on the initiation of sperm motility. Biol. Reprod. 19:1095. 
Uzu, G., J. L. Courtens and M. Courot. 1976. Quantitative analysis of ultrastructural abnormalities of spermatozoa from bulls of different fertility. VIII Intern'l. Cong. Anim. Reprod, and A. I. 4:748.

Vaidya, B. A., J. M. Bedford, R. H. Glass and J.M. Morris. Evaluation of the removal of tetracycline fluorescence from spermatozoa as a test for capacitation in the rabbit. J. Reprod. Fertil. 19:483.

Van Demark, N. L. E. Mercier, and G. W. Salisbury. 1945. The methylene blue reduction test and its relation to other measures of quality of bull semen. J. Dairy Sci. $28: 121$.

Vesselinovitch, S. D. 1960. Electrophoresis of spermatozoa and sex control. Cornell vet. 50:326.

Vickers, A. D. 1969. Delayed fertilization and the prenatal sex-ratio of the mouse. J. Reprod. Fertil. $20: 63$.

Vladimirskaja, E. M. 1966. Hormonal influence on gametes as a method of changing sex ratio in animals. Anim. Breed. Abstr. 35. No. 3273 .

Vladimirsjka, O. M. 1964. The method of the hormonal regulation of sex in artificially inseminated livestock. Anim. Breed. Abstr. 34. No. 967.

Volosevic, A. P. 1967. The action of biostimulators on sex ratio in the progeny of livestock. Anim. Breed. Abstr. 30. No. 3274 .

warren, C. 1940. Animal Sex Control. orange Judd Publishing Co., New York.

Weir, J. A. 1953. Association of blood pH with sex ratio in mice. J. Hered. 44:133.

Wells, M. E. and O. A. Owa. 1970. New technique for assessing acrosomal characteristics of spermatozoa. J. Dairy Sci. 53:227.

White, M. and E. Da Costa. 1960. Effect of cortisone on the maturation of the gonads and sex ratio of rats. Fed. Proc. 19:150 (Abstr.).

White, I. G. 1968. Mammalian semen. In E. S. E. Hafez (Ed.) Reproduction in Farm Animals (2nd Ed.) Lea \& Febiger, Philadelphia. 
Willett, E. L. and J. I. Ohms. 1955. Field trials with semen containing several combinations of antibacterial agents. J. Dairy Sci. 38:1360.

Williams, W. I. and A. Savage. 1927. Methods of determining reproductive health and fertility of bulls. Cornell vet. 17:374.

Wohlforth, E. 1961. Acrosome defect of boar spermatozoa. Anim. Breed. Abstr. 30. No. 2688.

Yanagimachi, R. 1969a. In vitro acrosome reaction and capacitation of golden hamster spermatozoa by bovine follicular fluid and its fractions. J. Exp. Zool. $170: 269$.

Yanagimachi, R. 1969b. In vitro capacitation of hamster spermatozoa by follicularfluid. J. Reprod. Fertil. $18: 275$.

Yanagimachi, R. 1970a. In vitro capacitation of golden hamster spermatozoa by homologous and heterologous blood sera. Biol. Reprod. 3:147.

Yanagimachi, R. 1970b. The movement of golden hamster spermatozoa before and after capacitation. $J$. Reprod. Fertil. 23:193.

Yanagimachi, $R$. and $Y$. D. Noda. 1970. Physiological changes in the post nuclear cap region of mammalian spermatozoa necessary to membrane fusion between sperm and egg cells. J. Ultrastruct. Res. 31:486.

Yanagimachi, R. and N. Usui. 1974. Calcium dependence of the acrosome reaction and activation of guinea pig spermatozoa. Exp. Cell Res. 89:161.

Zaugg, N. L. and J. O. Almquist. 1973. Motility of spermatozoa and control of bacteria in bovine semen diluents containing penicilin and neomycin or epicillin. J. Dairy Sci. 56:202. 


\section{VITA}

Stephen Dale Goodeaux was born in Lake Charles, Louisiana, on August 23, 1947. He received his elementary education at Oak Park Elementary and Oak Park Junior High and secondary education at LaGrange Senior High in Lake Charles. After graduation from high school in May, 1965, he enrolled in McNeese State University in Lake Charles and received a Bachelor of Science Degree in Animal Science in May, 1971. He received a Master of Science Degree in Reproductive Physiology from the Department of Dairy Science, Louisiana state University. On August 4, 1974 , he married Lora Lana Spears. One of the most memorable days of his life was July 14, 1976, the day his daughter Errin Marie was born. 
EXAMINATION AND THESIS REPORT

Candidate: Stephen Dale Goode aux

Major Field: $\quad$ Animal Science

Title of Thesis: Motility and Fertility of Stallion Spermatozoa Isolated in Bovine Serum Albumin

Approved:

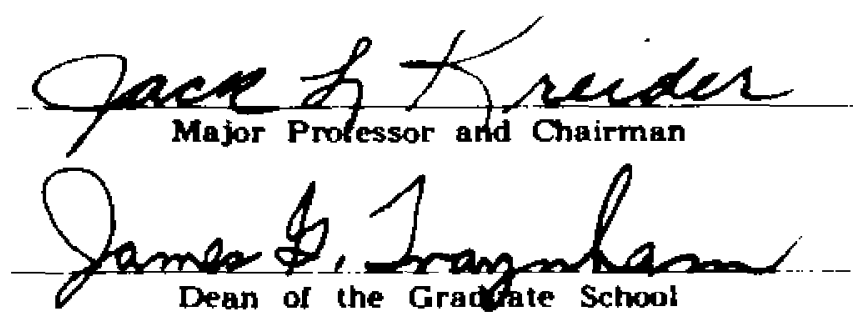

EXAMINING COMMITTEE:
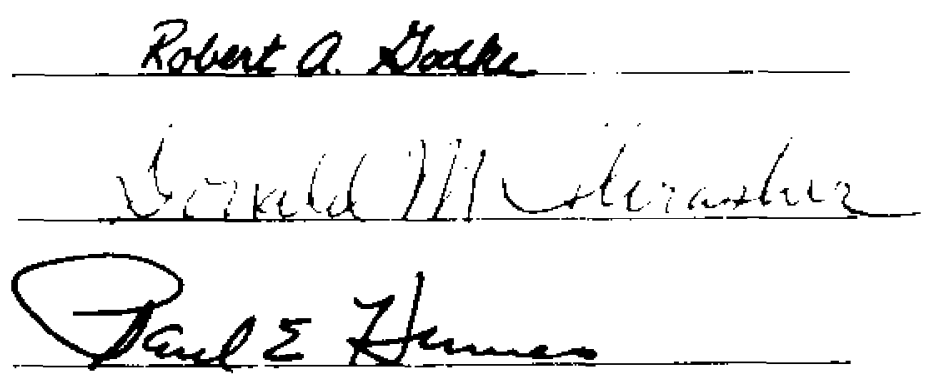

S. William B gr JwTrmen

Date of Examination:

August 21,1979 